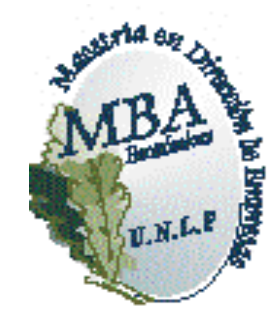

Universidad Nacional de La Plata

Facultad de Ciencias Económicas

MBA - Maestría en Dirección de Empresas

\title{
Marco Económico del Negocio
}

\section{Análisis de eficiencia del Sector Primario en la región de La Plata, Berisso y Ensenada}

Trabajo final para optar al título de Magister 


\section{Índice}

1. Planteo del Problema

2. Objetivos de la Investigación___ 2

3. Evaluación del Problema ___ 2

4. Alcance de la Investigación___ 4

5. Marco Teórico de Referencia___ 4

5.1. Antecedentes de la Investigación_____ 4

5.2 Bases Teóricas ___ _ 4

6. Metodología de la Investigación___ 11

6.1. Población y Muestra ___ 11

6.2. Tipo de Investigación ___ _ 11

6.3. Técnicas de Recolección de Datos ___ 12

6.4. Técnicas de Análisis ____ 12

7. Resultados de la Investigación ___ 12

Composición del sector primario_______ 13

Actividad Frutihortícola____ 14

Actividad Ganadera ________________ 18

Actividad Tambera_____ ¡Error! Marcador no definido.

Actividad Agrícola ___ 29

8. Conclusiones__ 33

9. Bibliografía___ 35 


\section{Planteo del Problema}

El desenvolvimiento de la actividad agropecuaria requiere contar con información económico-financiera oportuna para la toma de decisiones que satisfagan las necesidades del sector agropecuario como así también las de cualquier interesado en realizar inversiones y el sector gubernamental en sus distintos estamentos, en su rol de promotor de la actividad económica privada. En general para todos los sectores de la economía de la región conformada por los partidos de de La Plata, Berisso y Ensenada, se da una carencia y desorden significativo de datos e información oportuna y útil para la toma de decisiones, iniciativas de proyectos, y propósitos internos o externos de las organizaciones.

Las unidades económicas del sector Primario no cuentan con información, ya sea económica, estacional, estadística suficiente y sistematizada; que les permita compararse y superarse, solo se van adaptando a los requerimientos del mercado y del cliente, en base a atisbos de intuición empresarial. En la región no hay una base de datos e información fidedigna, que permita conocer con certeza el estado de situación real del sector.

Las empresas se crean para perdurar y para crecer. La meta del responsable principal es maximizar el valor de la empresa. Se entiende por eficiencia empresarial la suma del resultado de la inversión y la gestión del responsable principal que permite que la empresa esté funcionando a altos niveles de rendimiento, a costos adecuados.

Una información de mercado eficiente tiene efectos positivos para los productores y para los comerciantes. La información actualizada sobre los precios y otros factores de mercado permite a los productores negociar con los comerciantes y también facilita la distribución territorial de los productos desde las zonas rurales a las ciudades y entre los distintos mercados. La mayor parte de los gobiernos de los países en desarrollo han intentado proporcionar servicios de información de mercados a los productores, pero han experimentado problemas de sostenibilidad. Además, aún en los casos en que 
funcionan, el servicio prestado es a menudo insuficiente para permitir decisiones comerciales debido al intervalo de tiempo transcurrido entre la recogida de datos y su diseminación ${ }^{1}$.

No existe a nivel regional una base de datos de información actualizada y sistematizada del sector que permita efectuar un análisis de eficiencia o de estrategia empresarial, que atraiga la atención de inversores.

\section{Objetivos de la Investigación}

- Identificar parámetros de eficiencia del sector Primario de la región para poder caracterizar las notas salientes del contexto en este ámbito.

- Generar información relativa a la eficiencia del sector Primario de la región, capaz de hacer trascender características salientes de la realidad económica.

- Comparar los patrones de eficiencia regionales con otros externos como medida de referencia.

\section{Evaluación del Problema}

La productividad agropecuaria de una región es relevante por varios motivos, aparte de las ventajas evidentes de ser capaces de producir más alimento. La productividad de las explotaciones determina las posibilidades de crecimiento y competitividad en los mercados agropecuarios, así como las posibilidades de ahorro y la distribución de la renta. Además también influye de forma significativa en las migraciones interregionales. La productividad agropecuaria también influye en la eficiencia de la distribución de los recursos escasos eficiencia distributiva-. A medida que los productores adoptan las nuevas tecnologías y aparecen diferencias en la productividad, los más productivos experimentan incrementos de bienestar mientras que los menos productivos es

\footnotetext{
${ }^{1}$ Andrew W. Shepherd (2000) Servicios de Información de Mercados - Teoría y Práctica, FAO, Roma
} 
probable que cierren sus explotaciones y busquen cualquier otra actividad más lucrativa, colaborando al mejor uso de los recursos mencionado anteriormente ${ }^{2}$.

La productividad de este sector en una región -en caso de incrementarsegenera una ventaja comparativa en los productos agropecuarios, con lo cual la región puede ser capaz de producir la misma cantidad de producto a un costo menor que otras regiones competidoras. Por lo tanto, la región aumenta su competitividad en el mercado mundial, atrayendo más consumidores y aumentando el nivel de vida de sus habitantes.

El contexto actual caracterizado por la competitividad de los mercados, exige a los empresarios la mayor eficiencia posible en el manejo de su empresa. Una buena decisión se sustenta, principalmente, en un adecuado soporte informativo.

En estas circunstancias, la información ayuda al empresario con la identificación y la selección de las opciones más eficientes en el manejo de su empresa.

La falta de datos organizados y procesados para la toma de decisiones, en cuanto a la estructura económica de la región, es el fundamento para realizar el presente informe.

La información regional relativa a la actividad económica y a su nivel de eficiencia, es para los empresarios una herramienta muy valiosa a la hora de tomar decisiones proporcionando información relevante en lo referido al mercado regional y los clientes.

Es preciso contar con información veraz y fidedigna, para con ella analizar el escenario económico y direccionar la inversión sobre la base de pilares sólidos. De allí la importancia, conveniencia y trascendencia del presente estudio, dado

\footnotetext{
2 Mundlak, Yair, "Agricultural Productivity and Economic Policies: Concepts and Measurements," OECD Working Paper No. 75, OECD Development Center, August 1992, SourceOECD.org, 13 July 2007 (13-16).
} 
que se convierte en una herramienta trascendental, que habrá de permitir el acceso a la información real y estadística del sector.

Determinar los sectores de mayor eficiencia empresarial permite orientar los recursos siempre escasos de la economía, hacia aquellos sectores que mayor provecho pueden sacarle, esto es saber sacar partido de los nichos de mayor aprovechamiento no sólo para la propia empresa sino para todos los involucrados directa o indirectamente: proveedores, clientes, empleados y la comunidad en su conjunto.

\section{Alcance de la Investigación}

La Investigación se realizó en la región comprendida por los partidos de La Plata, Berisso, y Ensenada.

Para el cálculo de los indicadores de eficiencia se utilizaron valores brutos de producción y no valor agregado.

La investigación comprendió el año 2010.

\section{Marco Teórico de Referencia}

\subsection{Antecedentes de la Investigación}

La presente investigación reconoce como base el trabajo «Ventajas Competitivas y Oportunidades de Inversión - Tandil 1999/2000». Edición en conjunto entre la Universidad Nacional del Centro (Tandil) y Secretaría de Promoción y Desarrollo de la Municipalidad de Tandil. Lauría, Daniel (Director)

\section{$\underline{5.2 \text { Bases Teóricas }}$}

En 1936, partiendo de la publicación de "La Teoría General del Empleo, el Interés y el Dinero" de John M. Keynes, nace la Macroeconomía como ciencia dedicada al estudio del comportamiento agregado de una economía por medio 
de la observación de las tendencias globales, valiéndose para ello de medidas sintetizadoras de la actividad económica.

La principal variable macroeconómica de un país es el Producto o Ingreso Nacional, que no es otra cosa que el valor de la totalidad de los bienes y servicios finales producidos por una economía en un período determinado generalmente un año-.

Para generar el producto, las empresas utilizan la tierra, el capital, el trabajo y el gerenciamiento empresario, que son por ello denominados los factores de producción de la economía. Esos factores son propiedad de los individuos o familias, los cuales durante el proceso productivo perciben de las empresas un ingreso o remuneración correspondiente por su aplicación al mismo. La remuneración al factor tierra es la renta, la del capital es el interés, la del trabajo es el salario y la del gerenciamiento empresario, el beneficio.

La actividad económica la desenvuelven los llamados agentes económicos que, por el ejercicio de esa actividad, obtienen un ingreso. Estos agentes económicos realizan diversas funciones económicas (agricultura, industria, servicios, etc.) que conllevan un gran número de acciones económicas elementales y que dan lugar a flujos económicos que, además de su naturaleza específica (salarios, impuestos, formación de capital fijo), crean, transforman, intercambian, transfieren o extinguen valor económico.

Es innegable la influencia que el gerenciamiento empresario tiene como factor productivo en la determinación del Producto Bruto Interno de una economía, sea esta global, regional, sectorial o particular.

Al adentrarse en el gerenciamiento empresario como herramienta fundamental de la economía actual, resulta útil encuadrarlo dentro de algún marco y agregarle una medida de gestión.

Así puede enmarcárselo dentro de la Teoría Clásica de la Administración (Administration industrielle et générale, Fayol 1916), que a su vez por su 
definición misma da la medida de gestión. "Administrar" según Fayol es planear, organizar, dirigir, coordinar y controlar. Pone énfasis en la estructura y en la búsqueda del aumento de la eficiencia de la empresa (medida de gestión) a través de la forma y disposición de los órganos componentes de la organización y de sus interrelaciones estructurales.

"La eficiencia es muy importante. Sin ella, no habría organizaciones; con ella hay menos organizaciones...los expertos en eficiencia están más contentos cuando hay menos costos, incluso si esto implica que haya menos clientes", Mintzberg.

La eficiencia es un "paradigma importado" de la teoría económica, que ha orientado el trabajo de las organizaciones y sus dirigentes durante décadas, desde los trabajos de los economistas clásicos, Adam Smith y David Ricardo a mediados del siglo XVIII. Su planteamiento esencial es la relación entre insumos (gastos) y resultados (ingresos), su expresión es la reducción de los costos, o los costos mínimos. Tiene una lógica contundente, se tiene que "producir con los costos más bajos posibles", o dicho de otra forma, "obtener los mayores resultados con los mismos recursos (gastos)".

En las obras de los economistas clásicos el concepto de eficiencia se da por entendido sin que tenga una formulación explícita. Jevons desarrolló su "mecánica, de la utilidad", y aunque no hizo uso de la palabra eficiencia impuso el concepto como el problema central de la economía. A principios de siglo se desarrollaba un movimiento general en favor de la eficiencia aplicando los métodos de investigación científica a los sistemas de producción y distribución. Los estudios del costo, combinados con el estudio del movimiento y las fracciones de tiempo, proporcionaron una técnica que permite medir la eficiencia de la dirección y de los sistemas de producción. La dirección científica producía considerable economía como se demostró en los Estados Unidos en 1910 al reducir los gastos de los ferrocarriles en unos mil millones. De ahí que haya existido una especie de escuela de la eficiencia, entendiendo por tal el radio comprendido entre lo que se utiliza y lo que se produce, entre el esfuerzo y el rendimiento, entre los gastos y los ingresos, entre el costo y el 
beneficio o utilidad general resultante. Luther Gulick en The Efficient Life (1907) despertó en este sentido un vivo interés en el campo sanitario y psicológico; Josephine Goldmark publicó Fatique and Efficiency en 1912; Hugo Münsterberg, Psycology and Industrial Efficiency en 1913; Raymond Moley, The State Movement for Efficiency and Economy en 1918; C. J. Foreman, Efficiency and Scarcety Profits en 1930, todos ellos en los Estados Unidos, sin contar los que en Gran Bretaña y otros países siguieron esa tendencia, que en el orden práctico se tradujo en el taylorismo y otros sistemas de organización científica del trabajo.

Algunos autores se plantean la importancia de relacionar el término eficiencia (mirada interna a la empresa) con el término eficacia (mirada externa a la empresa). Este planteo queda en evidencia mayoritariamente en entornos turbulentos donde la empresa no puede dejar de preocuparse por lo que acontece fuera de ella.

La eficiencia actúa en el ámbito interno de la empresa, ahí es donde se puede trabajar para reducir sus gastos y optimizar los recursos. Pero ¿qué pasa en un entorno turbulento? se preguntan los especialistas, donde hay que prestar especial atención al "afuera" de la empresa, para ajustar las estrategias y acciones de manera de poder aprovechar las oportunidades o neutralizar las amenazas que se presenten.

Ante esto, Drucker afirma "No basta con hacer las cosas correctamente (eficiencia), hay que hacer las cosas correctas (eficacia)...".

La eficiencia hace énfasis en: los medios, hacer las cosas correctamente, resolver problemas, ahorrar gastos, cumplir tareas y obligaciones, capacitar a los subordinados, aplica un enfoque reactivo. Se concentra en cómo se hacen las cosas, de qué modo se ejecutan. La pregunta básica de la eficiencia es ¿Cómo se puede hacer mejor lo que se está haciendo? 
En la actualidad se entiende que el éxito del gerenciamiento empresario depende de la conjunción de tres medidas de gestión aplicadas al ámbito de los negocios, a saber: Eficacia + Eficiencia + Innovación y cambio.

Los empresarios deben buscar la mejor manera de hacer las cosas diarias, de optimizar el uso de recursos, de encontrar el mejor ¿Cómo?, pero siempre sin dejar de observar qué está ocurriendo en el mercado, atendiendo al ¿Qué?, a encauzar la estrategia empresarial. En este proceso aparece también como relevante la innovación y cambio permanente como cultura organizacional para poder ir adaptando la estrategia tanto interna como externa a los desafíos que plantea el mercado.

En el ámbito administrativo y gerencial, los términos eficiencia, eficacia y efectividad son utilizados frecuentemente.

- Eficiencia: Capacidad para lograr un fin empleando los mejores medios posibles: no siempre eficacia es sinónimo de eficiencia.

- Eficacia: Capacidad para obrar o para conseguir un resultado determinado.

- Efectividad: Capacidad para producir el efecto deseado: cincuenta por ciento de efectividad.

La eficiencia y la efectividad son dos adjetivos de naturaleza cualitativa, ambos aplicables a los procesos logísticos o cualquier sector en general, pues en condiciones ordinarias tiende a la optimización.

La efectividad es la cuantificación del cumplimiento de la meta, no importa si ésta se logra en forma eficiente o en forma efectiva.

En algunos casos, se acepta la efectividad como el logro de una meta acertadamente seleccionada en el proceso de planificación, es decir, la hipótesis que producía la solución idónea al problema o necesidad existente.

A partir de las definiciones de eficacia y eficiencia se pueden graficar las distintas situaciones que pueden presentarse y como afectan a la organización. 
Puede hacerse un análisis particular de cada sector, partiendo de la premisa que para que una organización funcione debe tener, al menos, un mínimo nivel de eficacia y eficiencia en sus procedimientos.

La búsqueda de un alto grado de eficacia, lograda en forma eficiente debe formar parte de la visión de la organización.

A modo de síntesis, y en términos generales, la palabra eficiencia hace referencia a los recursos empleados y los resultados obtenidos. Por ello, es una capacidad o cualidad muy apreciada por empresas $u$ organizaciones debido a que en la práctica todo lo que éstas hacen tiene como propósito alcanzar metas u objetivos, con recursos (humanos, financieros, tecnológicos, físicos, de conocimientos, etc.) limitados y (en muchos casos) en situaciones complejas y muy competitivas.

Existen diversas definiciones (aplicadas a la administración, economía y mercadotecnia) que han sido propuestas por diferentes autores.

Definición de Eficiencia:

- Aplicada a la Administración:

- Según Idalberto Chiavenato, eficiencia "significa utilización correcta de los recursos (medios de producción) disponibles. Puede definirse mediante la ecuación $E=P / R$, donde $P$ son los productos resultantes y $R$ los recursos utilizados"3.

- Para Koontz y Weihrich, la eficiencia es "el logro de las metas con la menor cantidad de recursos" ${ }^{4}$.

\footnotetext{
${ }^{3}$ Chiavenato Idalberto (2004) «Introducción a la Teoría General de la Administración», Séptima Edición, McGraw-Hill Interamericana, Pág. 52

${ }^{4}$ Koontz Harold y Weihrich Heinz (2004) «Administración Una Perspectiva Global», 12a.

Edición, McGraw-Hill Interamericana, Pág. 14
} 
- Según Robbins y Coulter, la eficiencia consiste en "obtener los mayores resultados con la mínima inversión"

- Para Reinaldo O. Da Silva, la eficiencia significa "operar de modo que los recursos sean utilizados de forma más adecuada"6.

- Aplicada a la Economía:

- Según Samuelson y Nordhaus, eficiencia "significa utilización de los recursos de la sociedad de la manera más eficaz posible para satisfacer las necesidades y los deseos de los individuos" ${ }^{\prime \prime}$.

- Para Gregory Mankiw, la eficiencia es la "propiedad según la cual la sociedad aprovecha de la mejor manera posible sus recursos escasos"

- Simón Andrade, define la eficiencia de la siguiente manera: "expresión que se emplea para medir la capacidad o cualidad de actuación de un sistema o sujeto económico, para lograr el cumplimiento de objetivos determinados, minimizando el empleo de recursos" ${ }^{\prime}$.

- Aplicada a la Mercadotecnia:

- Según el Diccionario de Marketing, de Cultural S.A., la eficiencia es el "nivel de logro en la realización de objetivos por parte de un organismo con el menor coste de recursos financieros, humanos y tiempo, o con máxima

\footnotetext{
5 Robbins Stephen y Coulter Mary (2005) «Administración», Octava Edición, Pearson Educación, Págs. 7

6 Oliveira Da Silva Reinaldo (2002) «Teorías de la Administración», International Thomson Editores, S.A. de C.V., Pág. 20

7 Samuelson Paul y Nordhaus William (2002) «Economía», Decimoséptima Edición, McGraw Hill Interamericana de España, Pág. 4

8 Mankiw Gregory (2004) «Economía», Tercera Edición, McGraw-Hill Interamericana de España, Pág. 4

9 Andrade Simón (2005) «Diccionario de Economía», Tercera Edición, Editorial Andrade, Pág. 253
} 
consecución de los objetivos para un nivel dado de recursos (financieros, humanos, etc.)"10.

- Según el Diccionario de la Real Academia Española:

- Eficiencia (Del lat. efficientĭa) es la capacidad de disponer de alguien o de algo para conseguir un efecto determinado ${ }^{11}$.

Para terminar, y teniendo en cuenta y complementando las anteriores propuestas, se plantea la siguiente definición general de eficiencia:

"Eficiencia es la óptima utilización de los recursos disponibles para la obtención de resultados deseados".

Por tanto, se puede decir que una empresa, organización, producto o persona es "eficiente" cuando es capaz de obtener resultados deseados mediante la óptima utilización de los recursos disponibles.

\section{Metodología de la Investigación}

\subsection{Población y Muestra}

Se trabajó sobre el universo de las unidades económicas para todas las subdivisiones del sector primario de la economía de la región considerada.

\subsection{Tipo de Investigación}

Se trata de una investigación de tipo exploratoria y de naturaleza cuantitativa, para tomar en cuenta aspectos de eficiencia regional.

\footnotetext{
${ }_{11}^{10}$ (1999) «Diccionario de Marketing», Cultural S.A., Pág. 106

11 sitio web de la «Real Academia Española», Diccionario de la Lengua Española - Vigésima Segunda Edición, obtenido en

http://buscon.rae.es/drael/SrvltConsulta?TIPO BUS=3\&LEMA=eficiencia , el 16 de enero, 2008
} 


\subsection{Técnicas de Recolección de Datos}

Para la elaboración del informe se utilizaron fuentes de información secundaria.

En tal sentido, las fuentes de datos han sido organismos gubernamentales nacionales -Ministerio de Agricultura, Ganadería, Pesca y Alimentación y Facultad de Ciencias Agrarias (UNLP)-, provinciales -Ministerio de Agricultura Ganadería y Pesca, Dirección Provincial de Economía Rural, Departamento Estadística- y Municipalidades de La Plata, Berisso y Ensenada -en su sector Producción-.

\subsection{Técnicas de Análisis}

Los indicadores de eficiencia obtenidos se refirieron a rindes por hectárea, engorde hacienda ( $\mathrm{kg} / \mathrm{cab} / \mathrm{año}$ ) y litros por tambo.

Una vez obtenidos los indicadores pertinentes, los resultados fueron volcados en tablas y gráficos con el análisis correspondiente.

\section{Resultados de la Investigación}

\section{Estructura Económica de La Plata, Berisso y Ensenada.}

La estructura productiva de la región conformada por los partidos de La Plata, Berisso y Ensenada, establecida por el Valor Bruto de Producción para el año 2010, determinó - para el sector Primario- un peso relativo del 3\% del total.

Para el año 2010 el Valor Bruto de Producción de la economía regional estuvo en el orden de los 14 mil millones de pesos (unos 3.500 millones de dólares estadounidenses). 


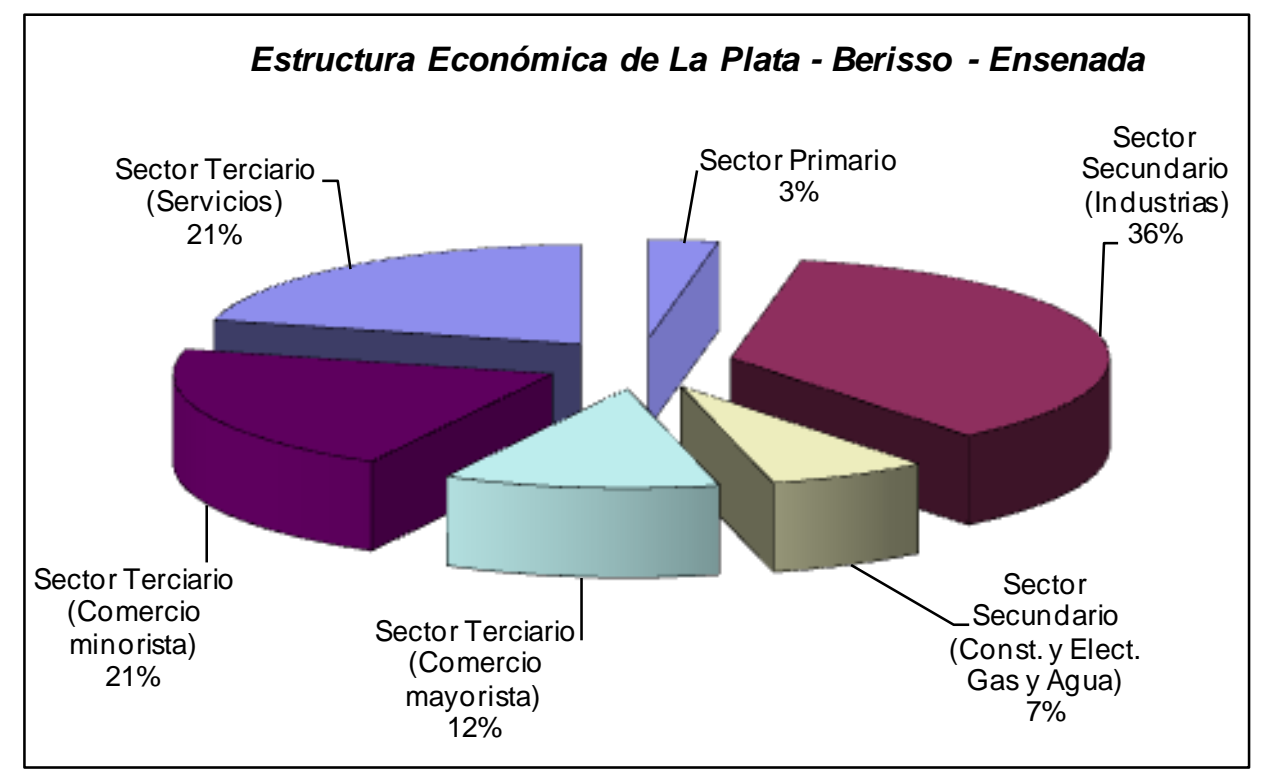

\section{Composición del sector primario}

El sector primario se compone principalmente de actividades referidas a la frutihorticultura, agricultura, ganadería y tambo.

Según el Valor Bruto de la producción del año 2010 se observa una absoluta primacía de la actividad Frutihortícola, seguida por la ganadería, tambo y finalmente agricultura.

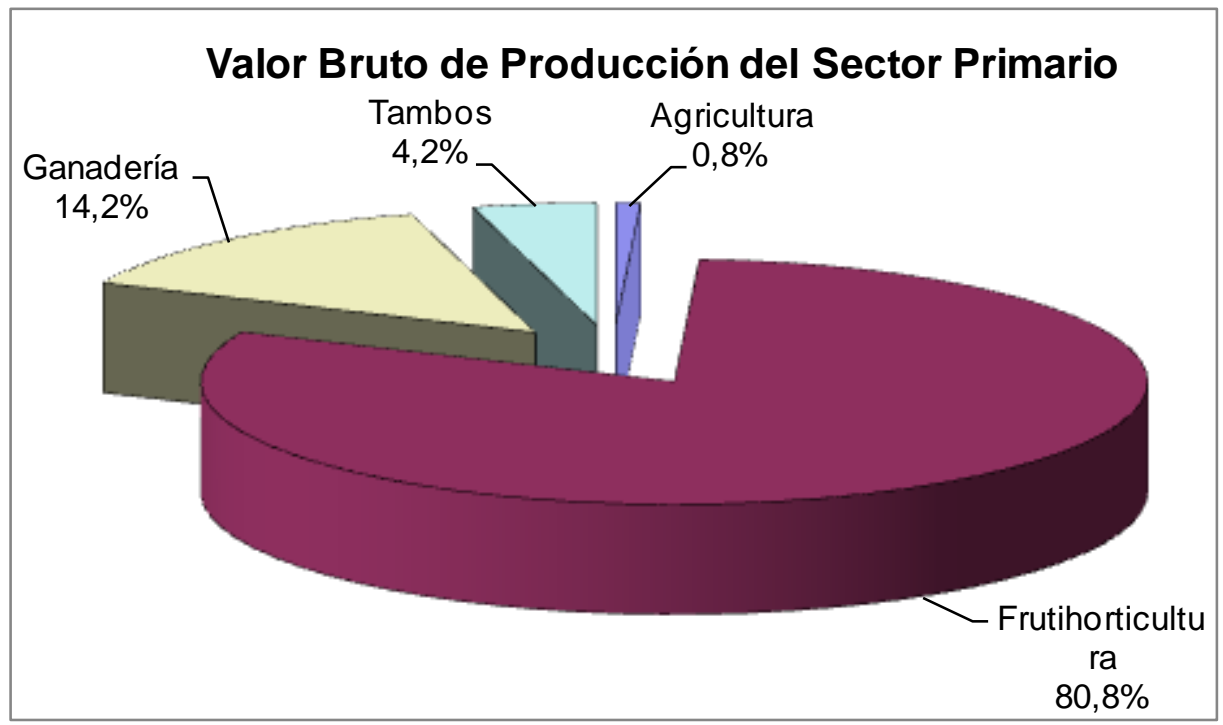




\section{Actividad Frutihortícola}

En la ciudad de La Plata se encuentra el Cinturón Hortícola Platense que representa una de las zonas de mayor influencia hortícola del Área Hortícola Bonaerense.

Para el 2010 la actividad hortícola de la capital bonaerense fue responsable del $72 \%$ de la producción regional del Área Hortícola Bonaerense y tuvo una participación del 58\% sobre la superficie implantada. Esto se traduce en una producción de 138.407 Tn y 4.902 hectáreas implantadas ${ }^{12}$.

La frutihorticultura de la región está caracterizada por tener un esquema de producción intensivo y altamente diversificado en cuanto a forma de producción y cantidad de especies que se cultivan.

El destino de la producción es casi exclusivamente el consumo en fresco. Esta situación tiene relación directa con la necesidad de abastecer diariamente a una vasta población en el área metropolitana. Con el fin de mantener una oferta constante tanto en cantidad como en diversidad de productos es que esta región ofrece hortalizas durante todo el año con algunos matices según época.

La comercialización de la producción se realiza fundamentalmente a través de diversos mercados concentradores que se ubican en distintas localidades del Gran Buenos Aires y La Plata.

\section{Evolución de la actividad en La Plata}

Con base en el año 1988 y al tomar como referencia los períodos 1998, 2005 y 2010, resulta evidente el crecimiento de la incidencia del Cinturón Frutihortícola Platense sobre el Área Frutihortícola Bonaerense, pasando del 28\% en 1988 al

\footnotetext{
12 Información obtenida de "La Producción Platense en el marco de su zona circundante (ABH)", Lic. Matías García, Departamento de Desarrollo Rural, Facultad de Ciencias Agrarias y Forestales, UNLP.
} 
Marco Económico del Negocio - Análisis de eficiencia del Sector Primario en la región de La Plata, Berisso y Ensenada

$72 \%$ en el $2010^{13}$ considerando las toneladas producidas, y del $28 \%$ al $58 \%$ considerando la superficie implantada en hectáreas.

A nivel de toneladas producidas y hectáreas implantadas la evolución ha sido la siguiente:

\section{Evolución de la Superficie destinada a Frutihorticultura}



\section{Evolución de la Producción Frutihortícola}



Años

\begin{tabular}{|l|r|r|r|r|}
\hline \multicolumn{1}{|c|}{ La Plata } & \multicolumn{1}{c|}{1988} & \multicolumn{1}{c|}{1998} & \multicolumn{1}{c|}{2005} & \multicolumn{1}{c|}{2010} \\
\hline Hectáreas & 4.753 & 4.021 & 3.709 & 4.902 \\
\hline Toneladas & 58.800 & 75.079 & 76.699 & 138.407 \\
\hline
\end{tabular}

\footnotetext{
${ }^{13}$ Información obtenida de "La Producción Platense en el marco de su zona circundante (ABH)", Lic. Matías García, Departamento de Desarrollo Rural, Facultad de Ciencias Agrarias y Forestales, UNLP.
} 
Parte de esta evolución de la zona platense se debe al proceso iniciado a mediados de los '90 y enfatizado durante el segundo lustro del nuevo siglo de fuerte adopción de la tecnología del invernáculo, en comparación con el resto del Área Hortícola Bonaerense.

También ha conllevado al desarrollo zonal de la actividad, el proceso de acumulación de capital en campesinos, tal el caso de los horticultores bolivianos en la zona bajo análisis. La migración desde Bolivia hacia la Argentina es algo tardía (década del '30), impulsada por el auge de las economías regionales y la alta demanda de cosecheros. Se destacaban el trabajo en el Norte del país (caña de azúcar y tabaco), junto a la vendimia y la recolección de ajo en la región cuyana. Comenzado ya la segunda parte del siglo pasado, la migración boliviana se intensifica y comienza a dirigirse hacia el Área Metropolitana de Buenos Aires. El cambio del destino se debió al proceso de mecanización ahorradora de mano de obra que mostraba el sector agropecuario en general, como así también por las mejores condiciones laborales (en relación a Bolivia y a los mercados de trabajo de las provincias del interior del país) que caracterizó a la etapa de industrialización sustitutiva de importaciones en la Argentina. Finalmente, en los años '90, con un tipo de cambio fuertemente sobrevaluado, se observa una pujante corriente inmigratoria boliviana que encuentra un espacio de inserción en el mercado de trabajo hortícola de los cordones de las grandes ciudades. La misma muestra gran influencia en la conformación de redes, como en la consolidación de las preexistentes.

La Plata no sólo ganó espacio en el gran mercado bonaerense, sino que también amplió los destinos de su producción a regiones otrora difíciles de ingresar, tales como la ciudad de Santa Fé, Rosario y la Costa (área de influencia de Mar de Plata).

La expansión en la superficie bajo cubierta y su correlato en la producción por la altísima productividad le permite a La Plata ser hoy día el responsable de más del $72 \%$ de la oferta del cinturón que provee al GBA. El nivel tecnológico, 
volumen, calidad y período de oferta hacen de La Plata la principal región productiva de hortalizas frescas del país ${ }^{14}$.

La producción en toneladas y precio (que determinan el valor bruto de la producción de esta actividad) para el año 2010 abierta por tipo de cultivos es la siguiente:

\begin{tabular}{|c|c|c|c|}
\hline \multirow{2}{*}{ Cultivo } & \multicolumn{3}{|c|}{ Año 2010} \\
\hline & Ton & Precio & VBP \\
\hline Acelga & $5.329,01$ & 697,08 & $3.714 .764,84$ \\
\hline Apio & $3.150,81$ & $1.255,16$ & $3.954 .770,58$ \\
\hline Cebolla de Verdeo & $1.109,90$ & $4.951,25$ & $5.495 .396,25$ \\
\hline Espinaca & $3.053,55$ & $10.100,00$ & $30.840 .895,52$ \\
\hline Hinojo & 837,53 & $1.230,00$ & $1.030 .158,64$ \\
\hline Lechuga & $24.618,55$ & $1.607,50$ & $39.574 .316,29$ \\
\hline Perejil & 384,83 & $3.930,00$ & $1.512 .381,58$ \\
\hline Puerro & 669,06 & $3.430,00$ & $2.294 .877,20$ \\
\hline Radicheta & 163,03 & $3.120,00$ & $508.654,97$ \\
\hline Otras Hortalizas de Hoja & 387,25 & $2.617,81$ & $1.013 .744,48$ \\
\hline Brócoli & 697,58 & $4.130,00$ & $2.880 .989,18$ \\
\hline Coliflor & 501,21 & 891,92 & $447.038,51$ \\
\hline Nabo & 0,98 & $1.920,00$ & $1.888,40$ \\
\hline Rabanito & 3,64 & $1.920,00$ & $6.982,68$ \\
\hline Repollo Blanco & 531,83 & 963,75 & $512.547,92$ \\
\hline Repollo Colorado & 410,47 & 963,75 & $395.588,57$ \\
\hline Repollito de Bruselas & 75,16 & 753,20 & $56.606,80$ \\
\hline Ajo Blanco & 0,07 & 711,67 & 48,43 \\
\hline Anco/Anquito & 573,60 & $1.445,00$ & $828.851,84$ \\
\hline Batata & 148,81 & $1.144,17$ & $170.260,33$ \\
\hline Cebolla Valenciana & 11,75 & 797,30 & $9.368,54$ \\
\hline Papa & 198,49 & $1.375,00$ & $272.917,31$ \\
\hline Remolacha & 360,77 & 872,50 & $314.769,14$ \\
\hline Zanahoria & 6,80 & 980,00 & $6.663,55$ \\
\hline Zapallo & 61,35 & $1.840,00$ & $112.882,12$ \\
\hline Alcaucil & $5.132,63$ & $3.520,00$ & $18.066 .865,51$ \\
\hline Arveja & 104,71 & $3.260,00$ & $341.358,34$ \\
\hline Berenjena & $1.194,73$ & $2.804,17$ & $3.350 .218,83$ \\
\hline Chaucha & $1.032,80$ & $3.801,67$ & $3.926 .370,73$ \\
\hline Choclo & $2.780,72$ & $2.756,67$ & $7.665 .525,53$ \\
\hline Espárrago & 6,23 & $4.509,40$ & $28.095,07$ \\
\hline Frutilla & 141,97 & $8.500,00$ & $1.206 .732,63$ \\
\hline Haba & 175,94 & $2.070,00$ & $364.205,39$ \\
\hline Melón & 248,20 & $3.990,00$ & $990.301,00$ \\
\hline Pepino & 450,12 & $2.889,17$ & $1.300 .474,20$ \\
\hline Pimiento & $17.874,85$ & $4.265,00$ & $76.236 .231,43$ \\
\hline Sandía & 254,82 & $1.500,00$ & $382.230,99$ \\
\hline Tomate Perita & $9.880,31$ & $1.950,83$ & $19.274 .843,79$ \\
\hline Tomate Redondo & $39.274,78$ & $1.960,83$ & $77.011 .297,13$ \\
\hline Otros tomates & $14.352,74$ & $1.960,83$ & $28.143 .325,99$ \\
\hline Zapallo de Tronco & $2.187,57$ & $1.840,00$ & $4.025 .136,38$ \\
\hline Otras Hortalizas de Flores, Frutos y Tallos & 27,93 & $2.433,08$ & $67.962,50$ \\
\hline TOTAL & $138.407,07$ & & $338.338 .539,10$ \\
\hline
\end{tabular}

Fuente: Elaboración propia sobre la base de datos Fac. Cs. Agrarias y Forestales y Mercado Central BA

\footnotetext{
14 “La Producción Platense en el marco de su zona circundante (ABH)", Matías García, Becario del Conicet.
} 
Marco Económico del Negocio - Análisis de eficiencia del Sector Primario en la región de La Plata, Berisso y Ensenada

\section{Indicadores de eficiencia actividad Frutihortícola.}

Como surge de lo expuesto anteriormente, la actividad Frutihortícola platense a través de las últimas décadas ha ido creciendo en importancia, tanto a nivel toneladas como hectáreas implantadas, respecto del Área Hortícola Bonaerense constituyéndose hoy día en el pilar de esta actividad para dicha área.
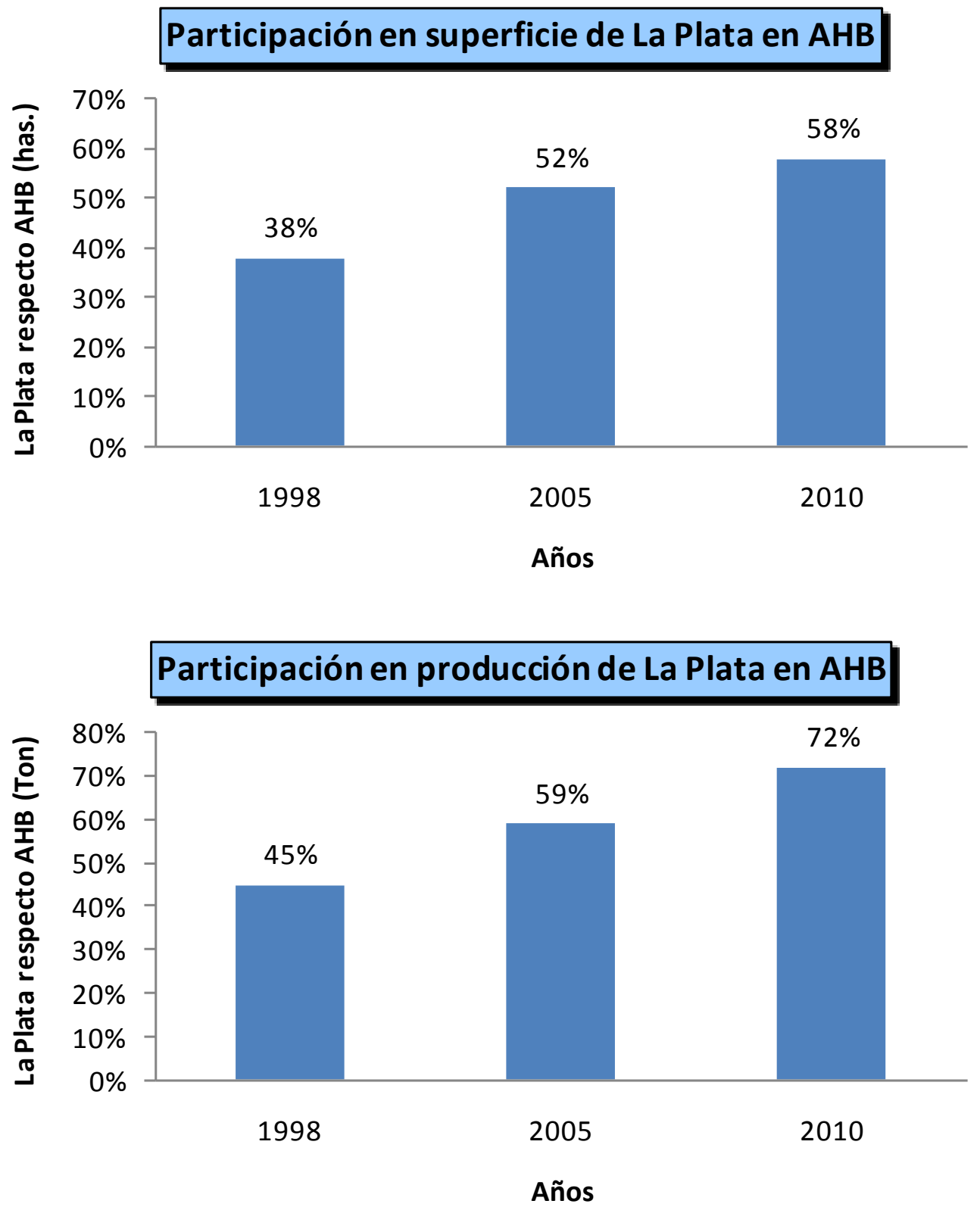

Una relación entre superficie y producción de La Plata respecto del AHB, indica una evolución favorable a La Plata en cuanto a productividad comparada. 
Marco Económico del Negocio - Análisis de eficiencia del Sector Primario en la región de La Plata, Berisso y Ensenada

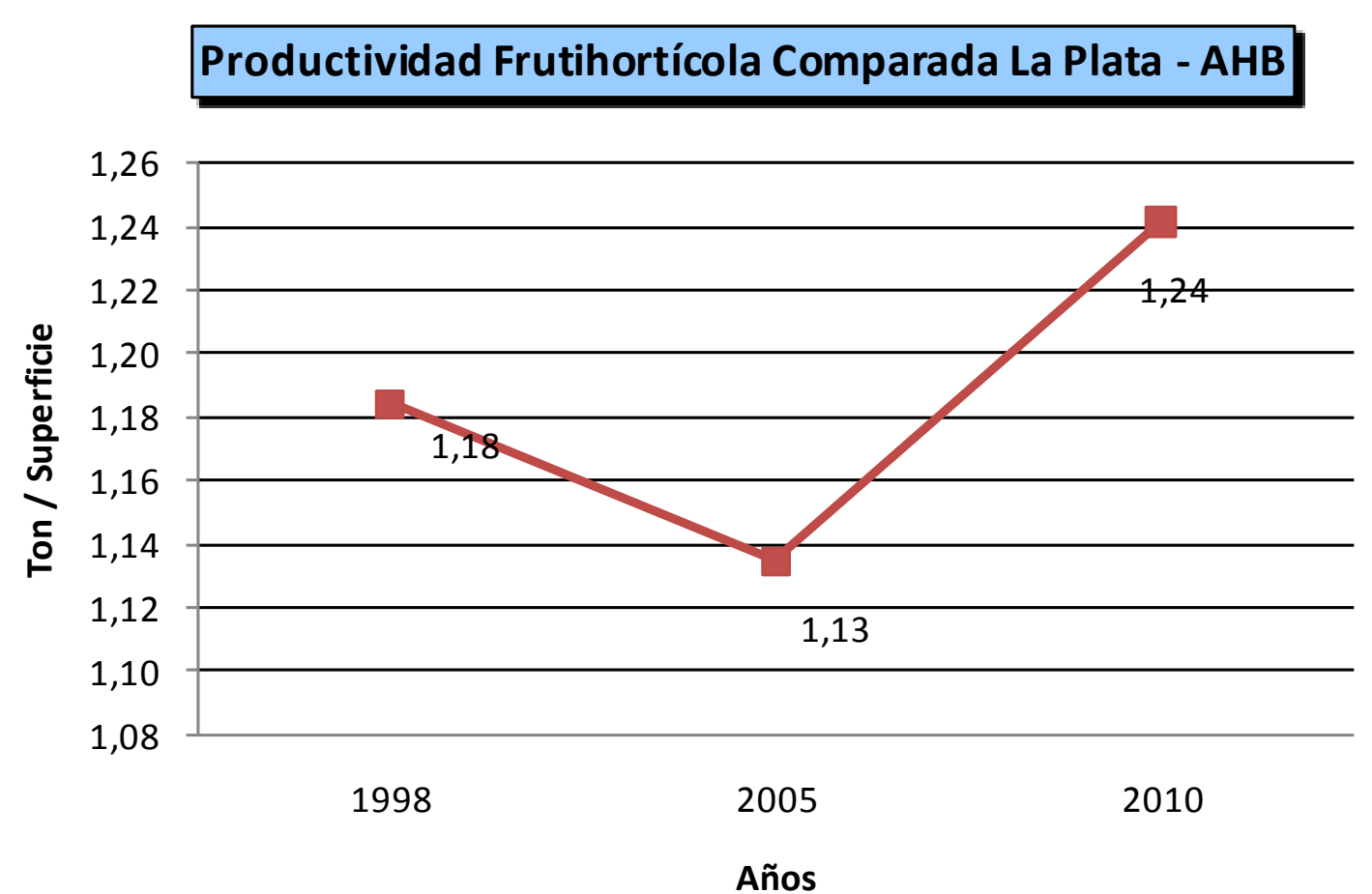

El indicador de la productividad de esta actividad está dado por el rinde por hectárea, y la productividad de la actividad Frutihortícola platense respecto del AHB ha sido la siguiente:

\section{Productividad Frutihortícola AHB - La Plata}

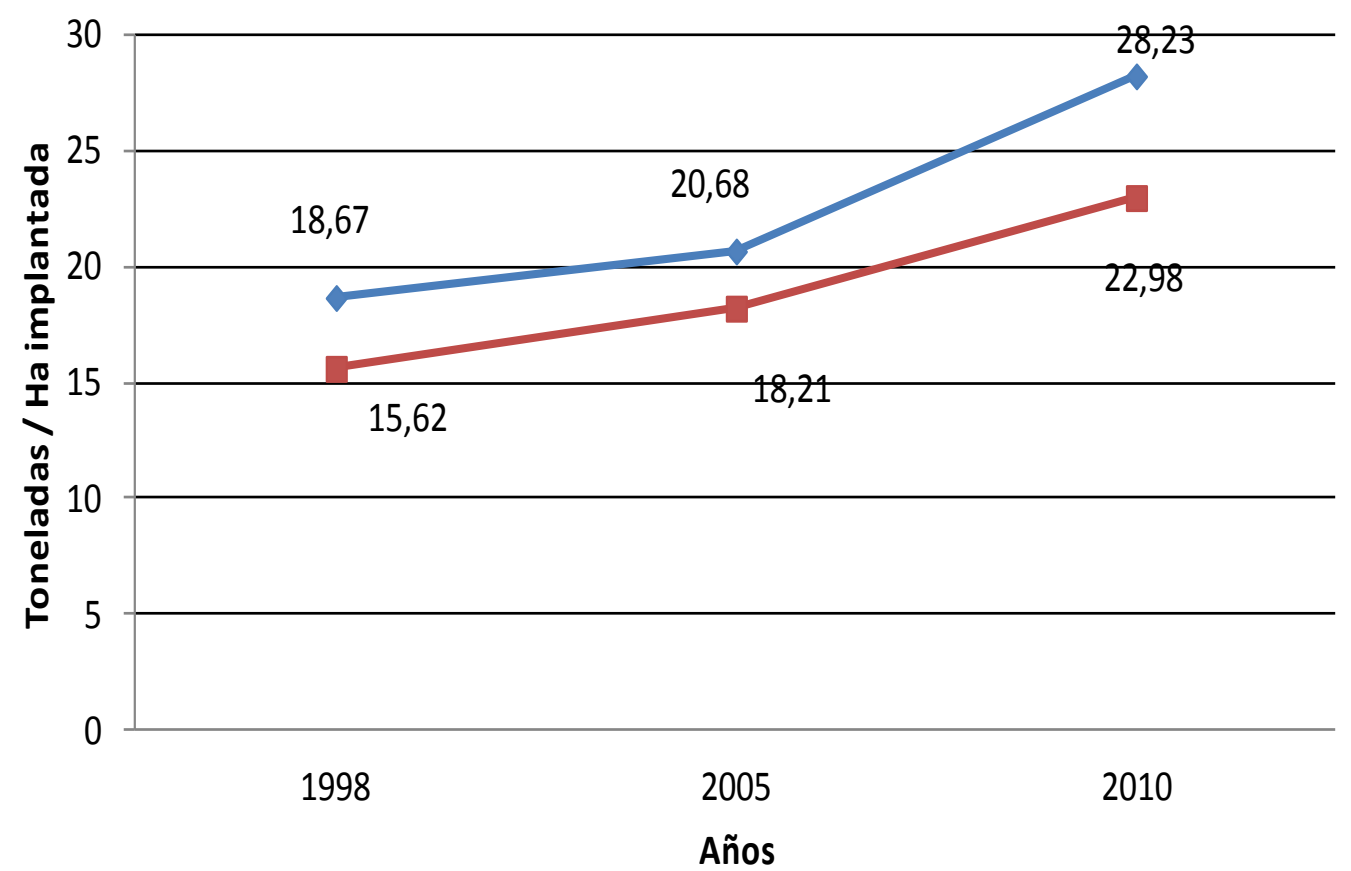

$\rightarrow$ La Plata $\rightarrow$-Area Hortícola Bonaerense 
Marco Económico del Negocio - Análisis de eficiencia del Sector Primario en la región de La Plata, Berisso y Ensenada

\section{Actividad Ganadera}

Las existencias bovinas en la Provincia de Buenos Aires para el año 2010 ascendieron a un total de 15.982.934 cabezas de ganado bovino.

Los partidos de La Plata, Berisso y Ensenada aportaron 65.881 cabezas a dicho stock provincial $(0,41 \%)$. El que más influencia tiene de estos tres partidos es La Plata con 62.258 cabezas.

\section{Total existencias ganaderas en la región - Año 2010}



La composición en cada Partido para el año 2010 ha sido:

Composición existencias ganadería bovina en La Plata - Año 2010

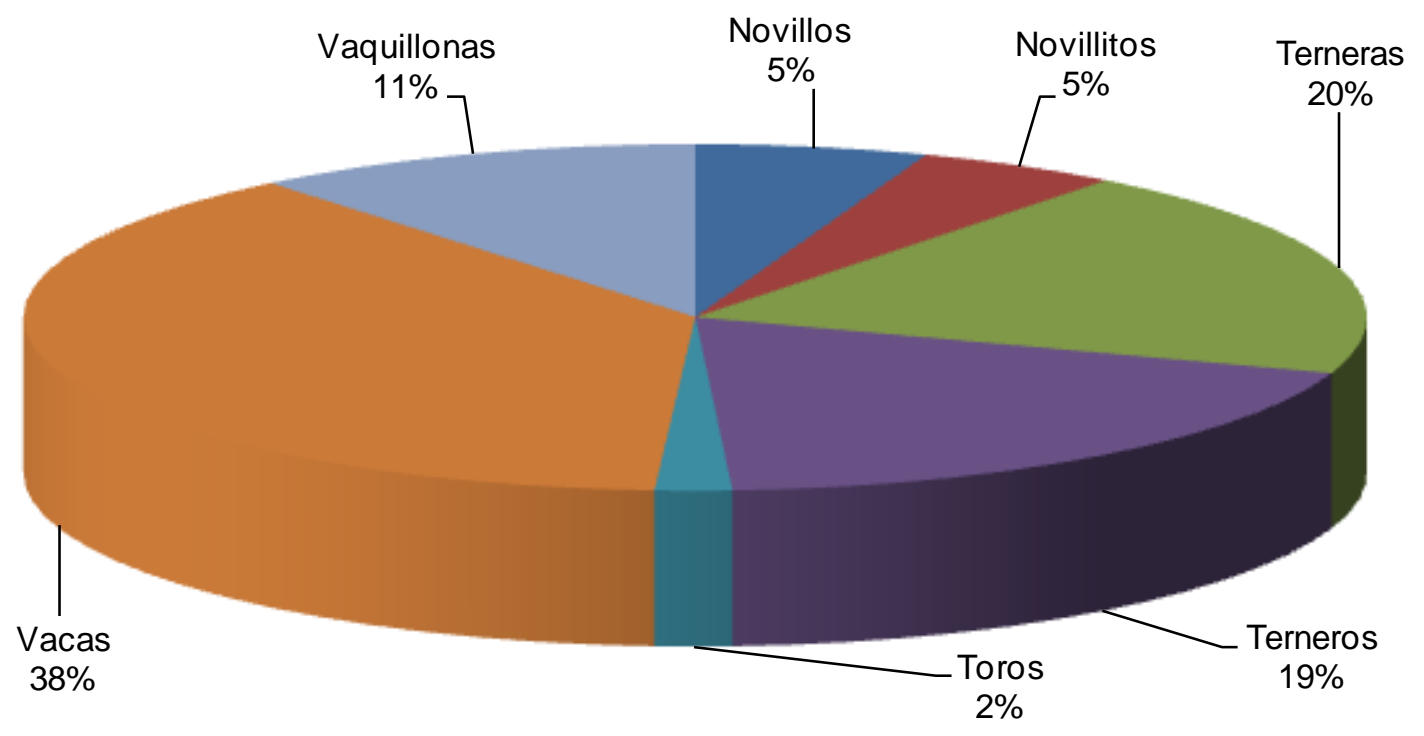


Marco Económico del Negocio - Análisis de eficiencia del Sector Primario en la región de La Plata, Berisso y Ensenada

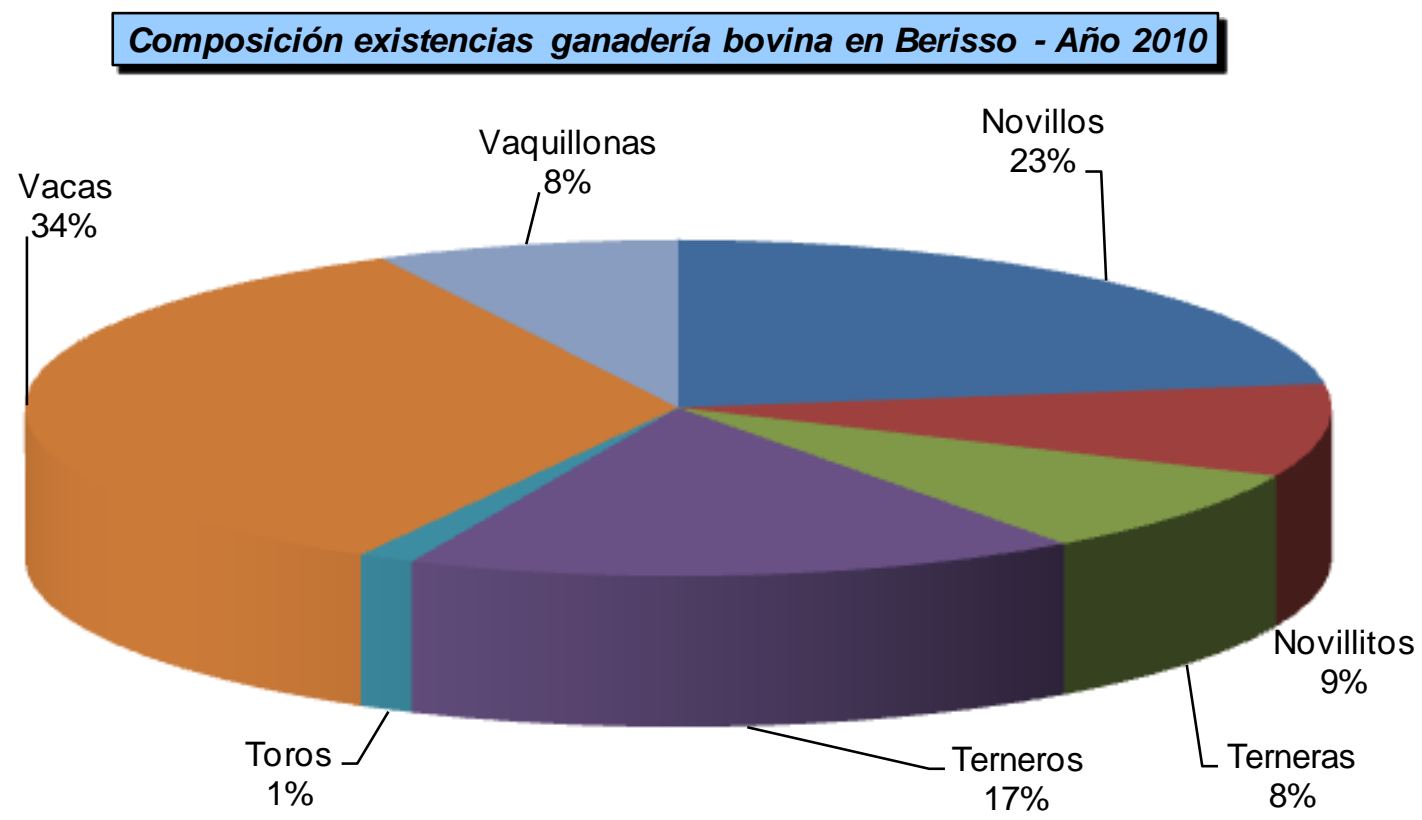

Composición existencias ganadería bovina en Ensenada - Año 2010

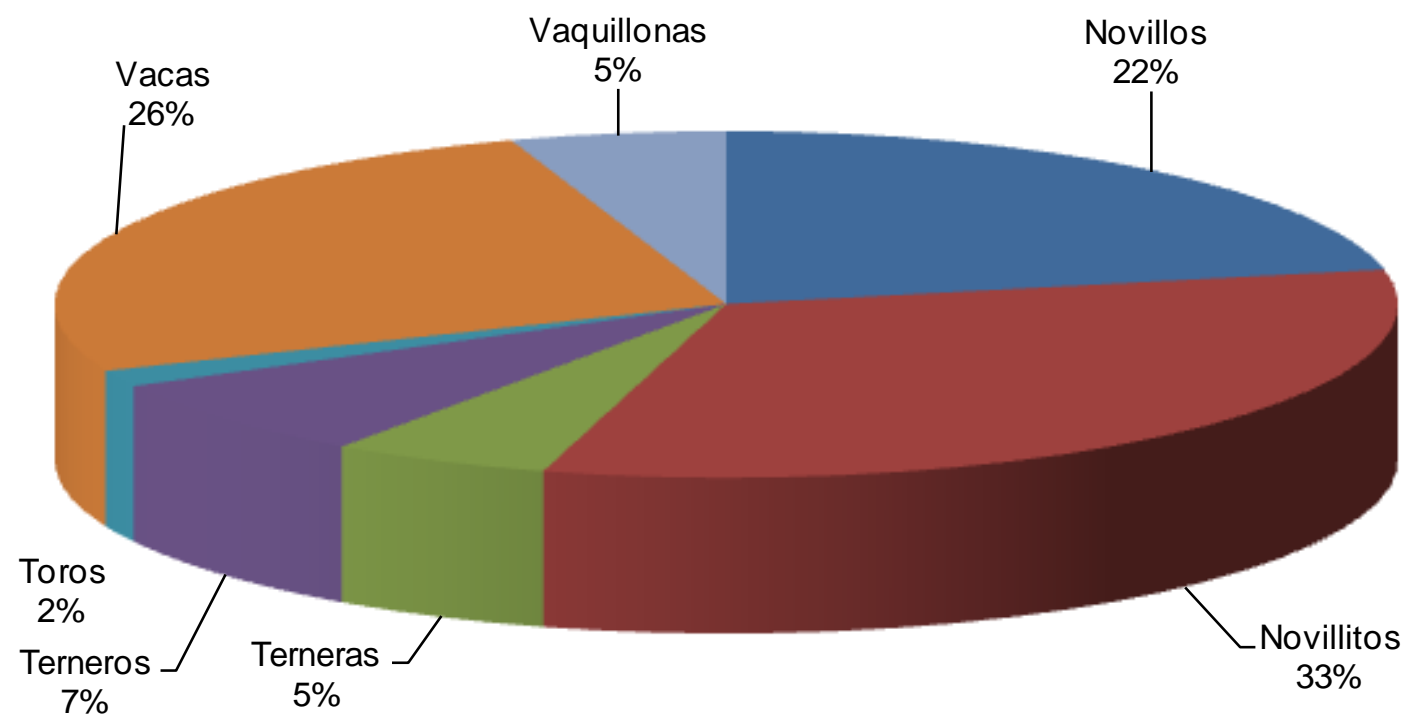


Marco Económico del Negocio - Análisis de eficiencia del Sector Primario en la región de La Plata, Berisso y Ensenada

La evolución de las distintas categorías de las existencias para el partido de La Plata, para los períodos 2003-2010 ha sido la siguiente:

\section{Novillos La Plata Evolución Existencias}

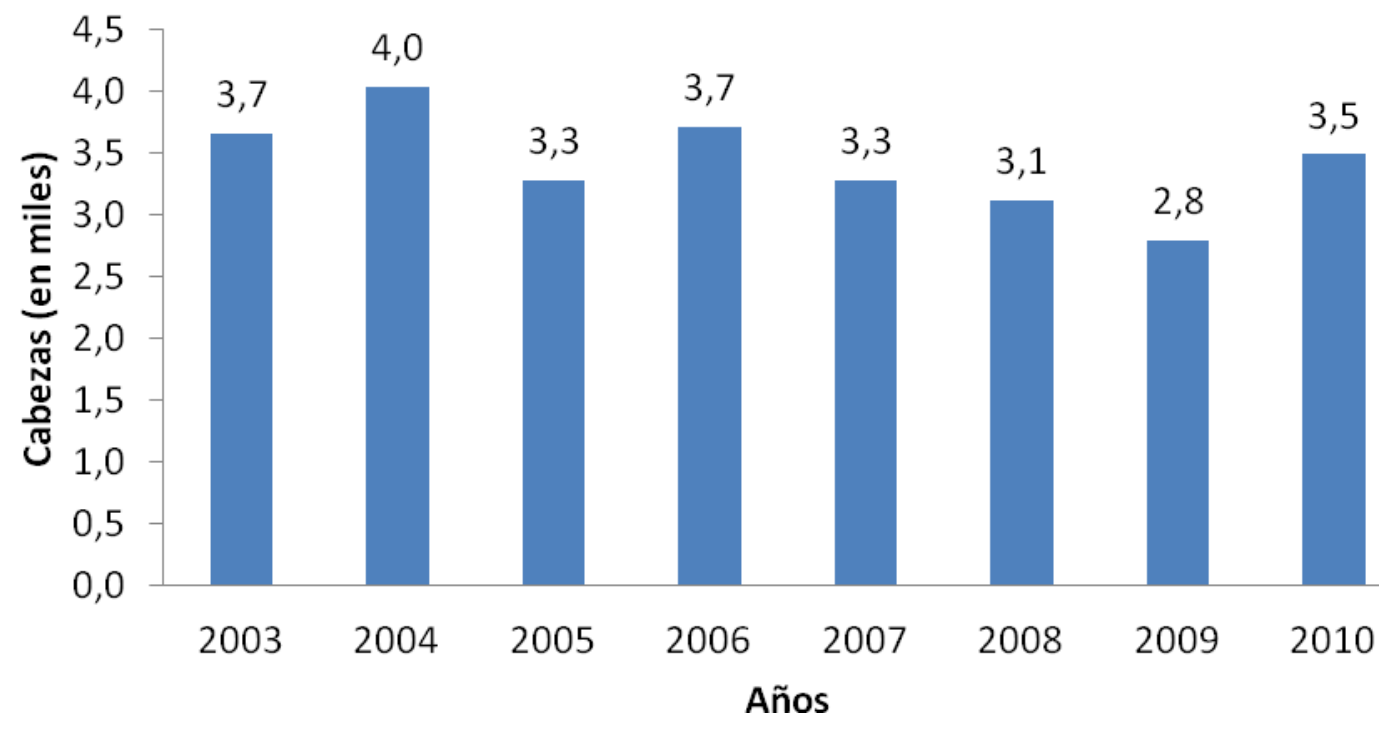

\section{Novillitos La Plata Evolución Existencias}

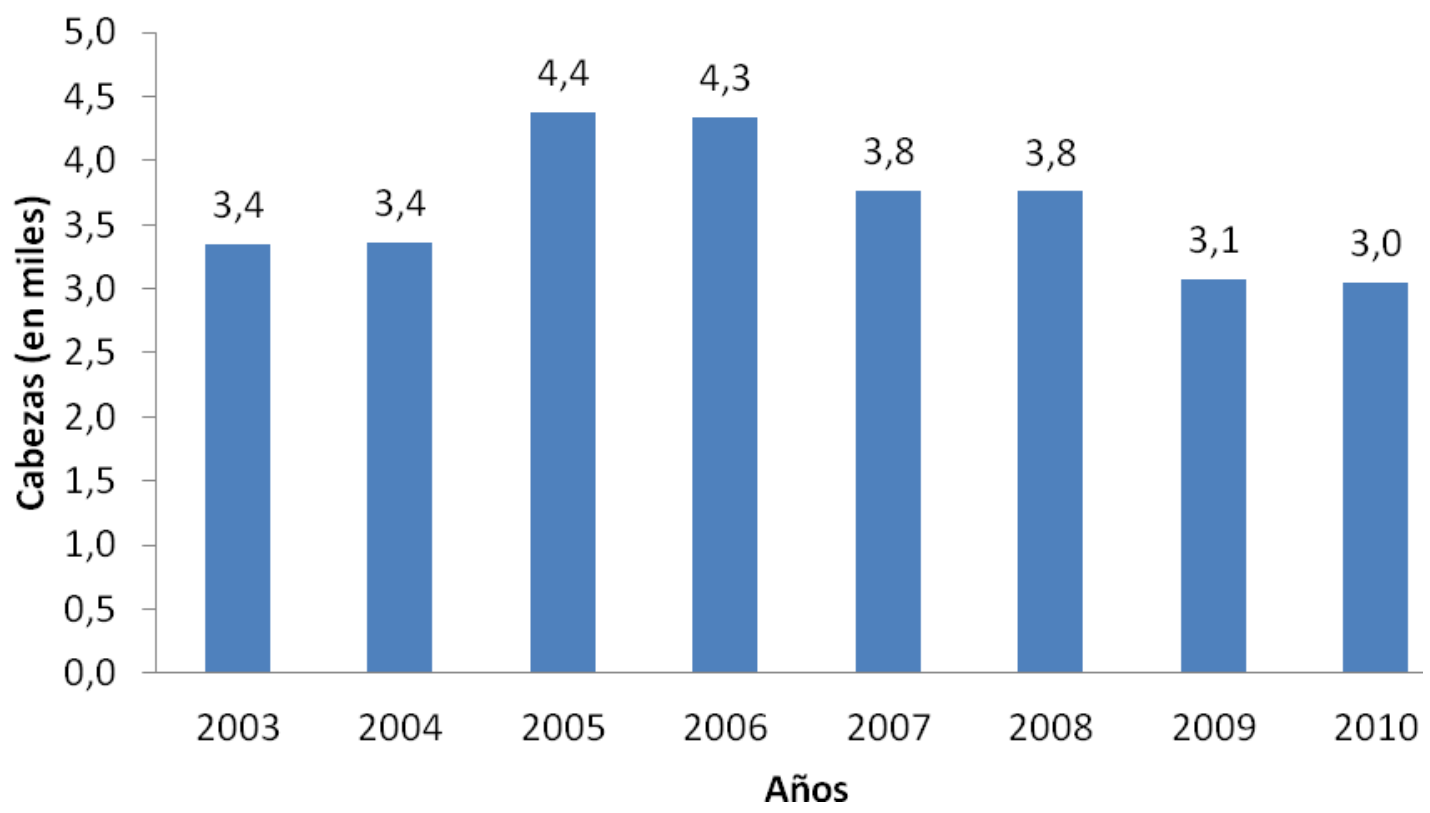


Terneras La Plata Evolución Existencias

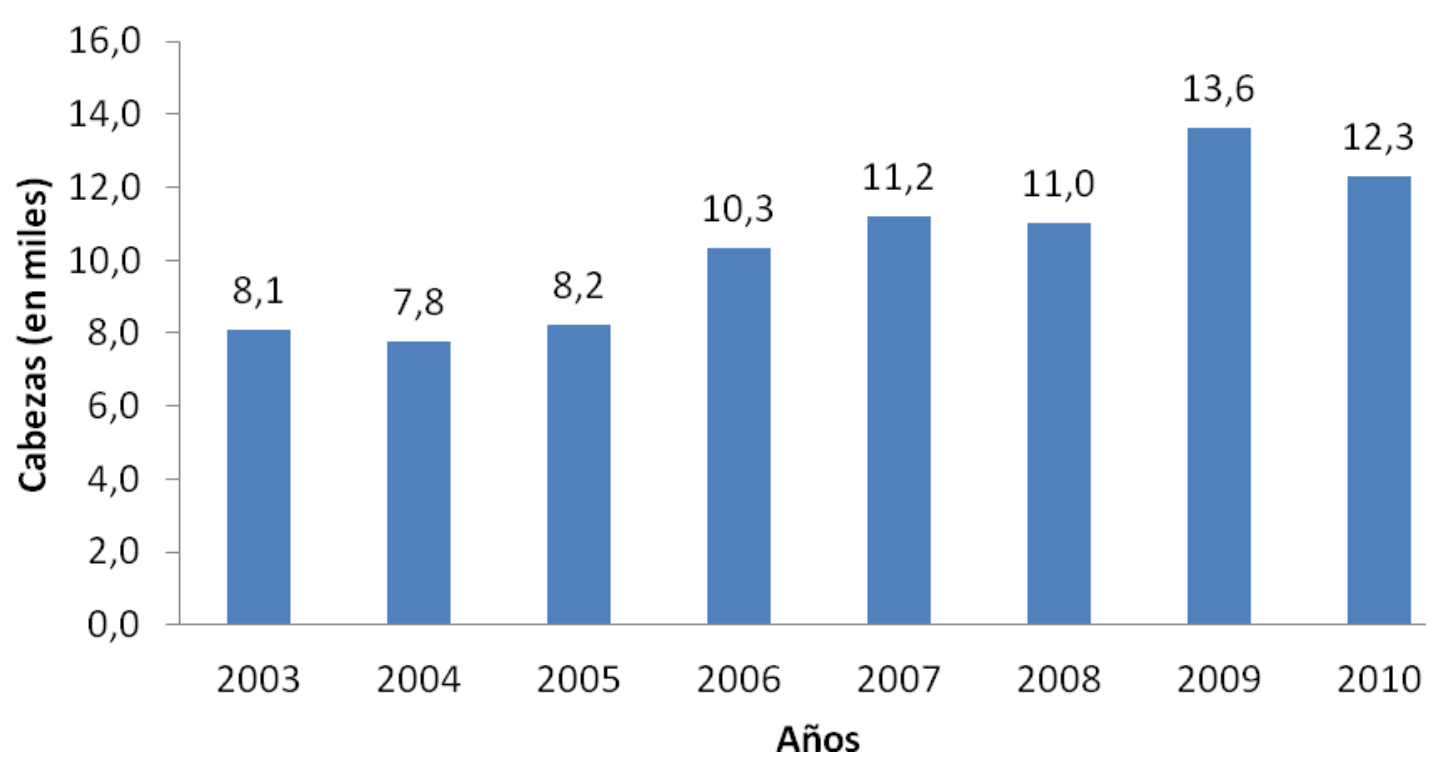

Terneros La Plata Evolución Existencias

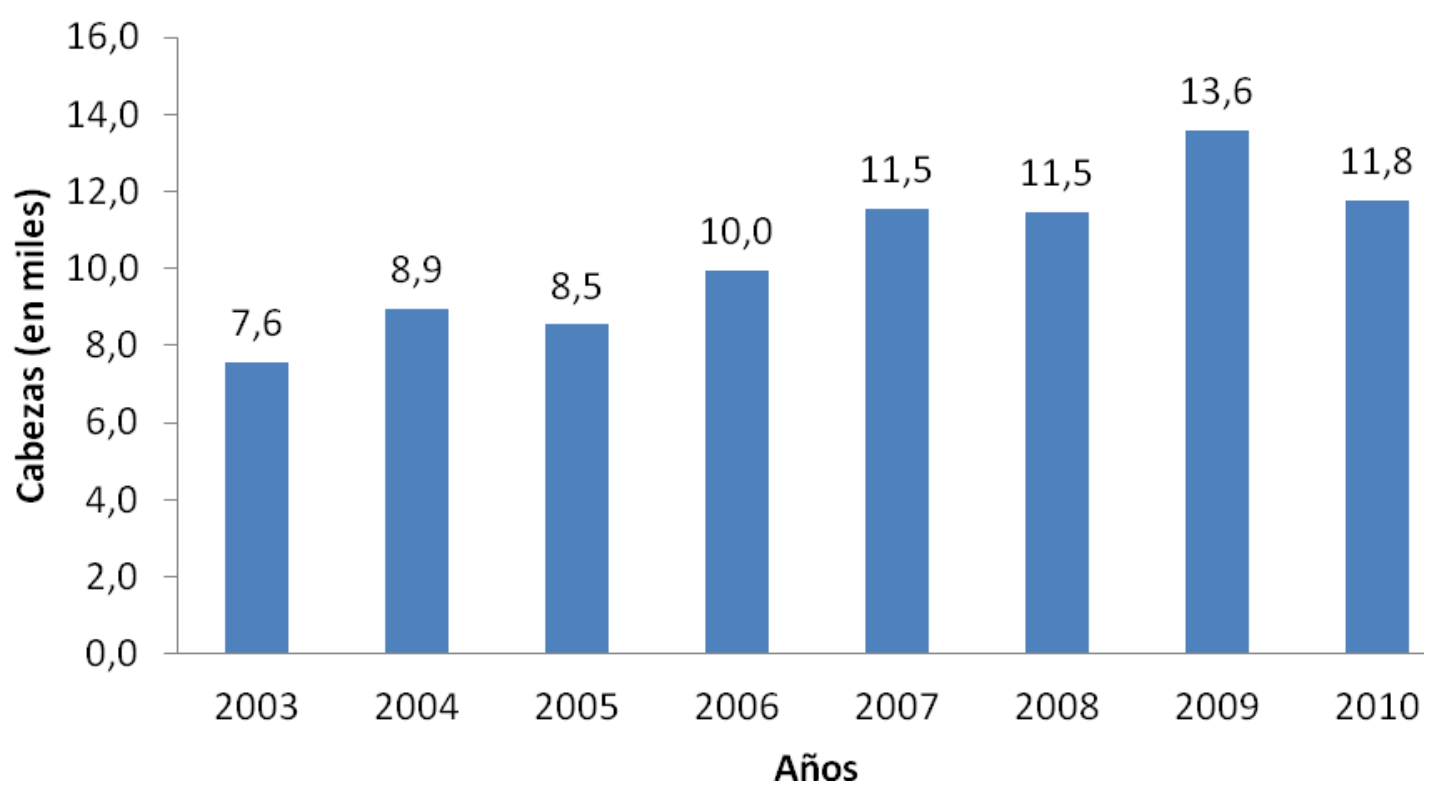


Marco Económico del Negocio - Análisis de eficiencia del Sector Primario en la región de La Plata, Berisso y Ensenada

\section{Vacas La Plata Evolución Existencias}

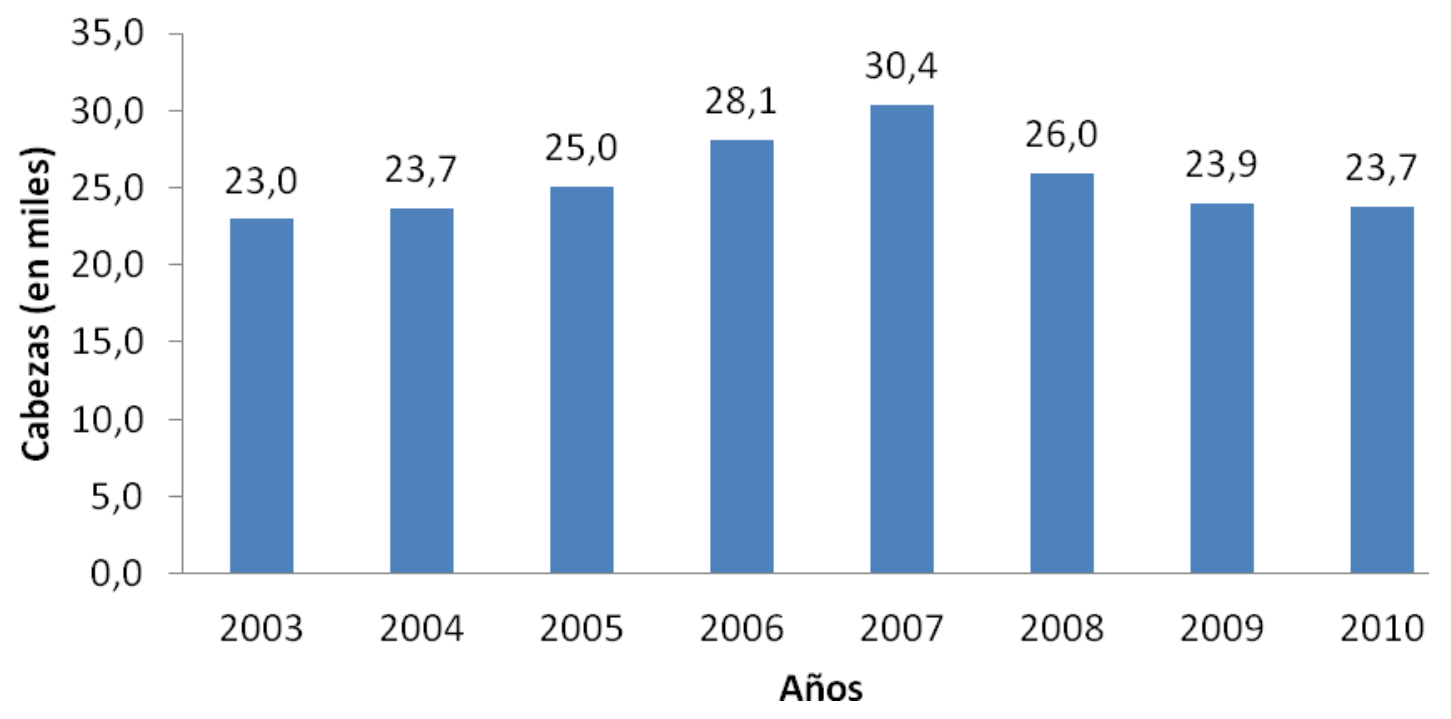

Vaquillonas La Plata Evolución Existencias

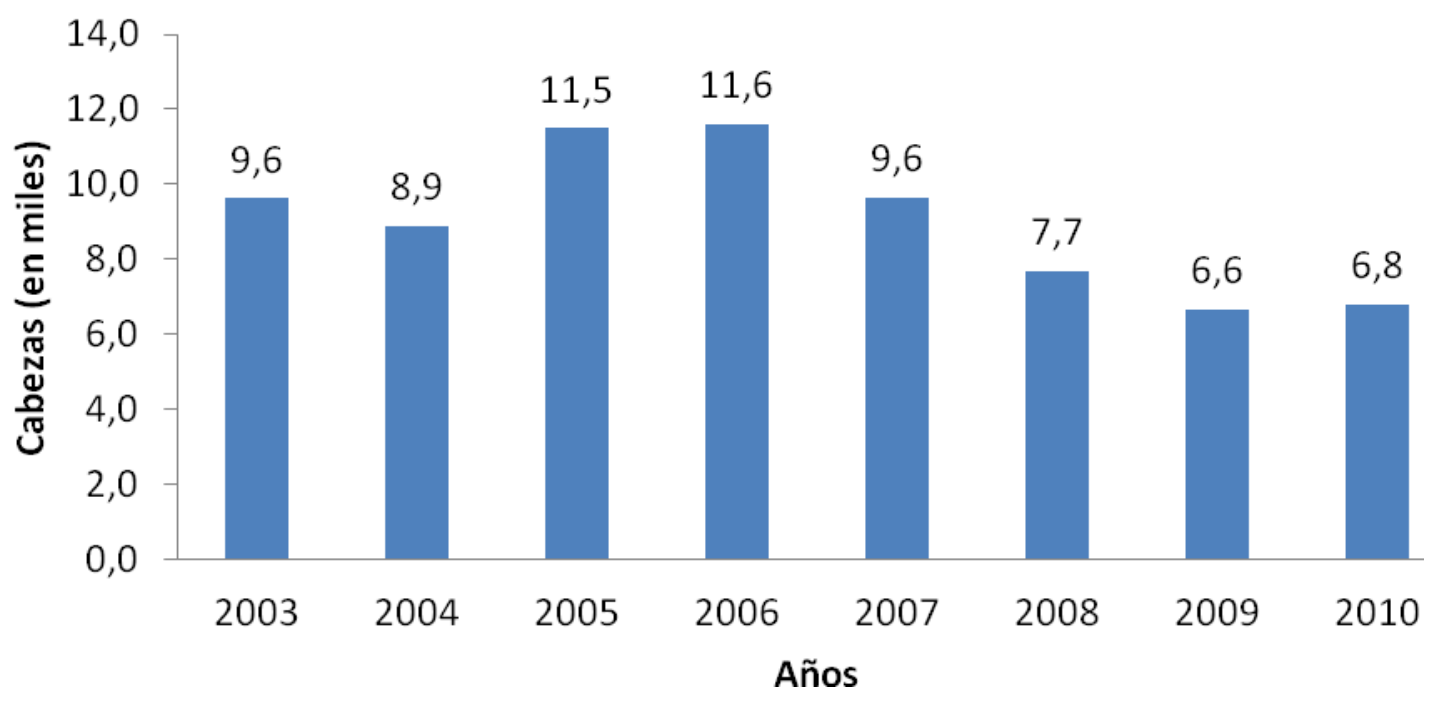




\section{Toros La Plata Evolución Existencias}

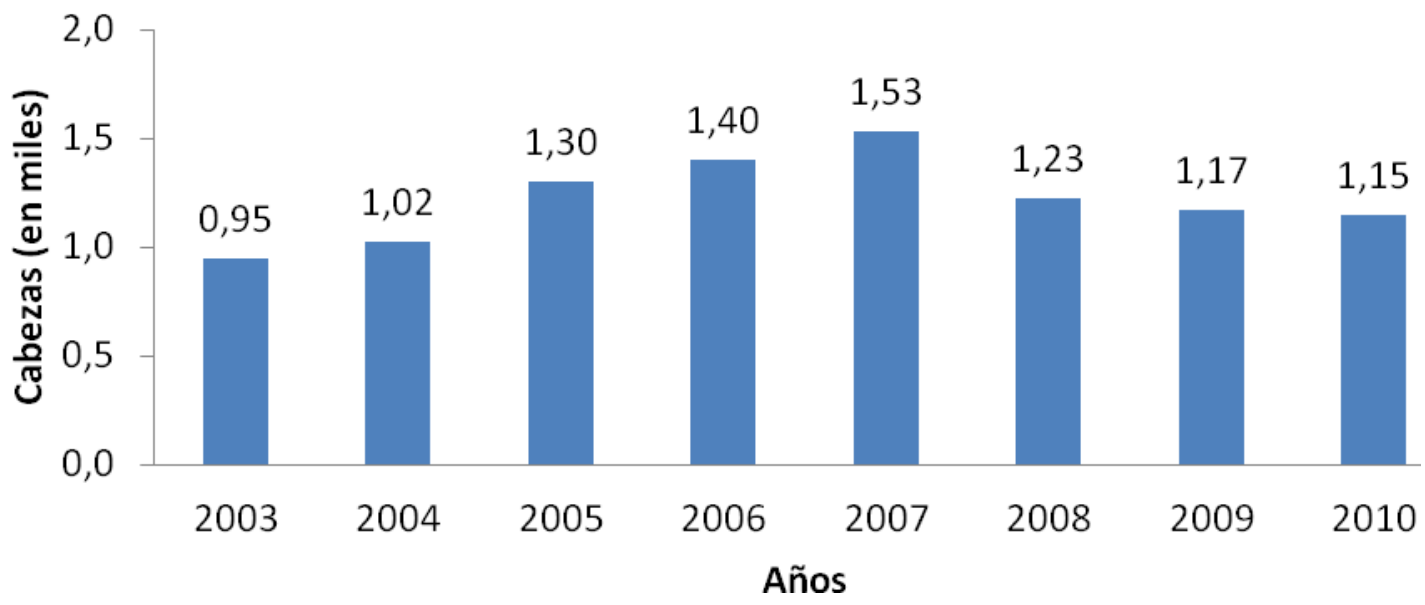

A partir de la premisa de dedicar un $75 \%$ a invernada y un $25 \%$ a reposición y con terminación de categorías en los pesos que siguen, se ha realizado la siguiente estimación del Valor Bruto de Producción.

\begin{tabular}{|l|r|r|r|r|r|}
\hline & Cabezas & $\begin{array}{c}\text { Peso Term. } \\
\text { (Kgs) }\end{array}$ & $\begin{array}{c}\text { Peso Total } \\
\text { (Kgs) }\end{array}$ & $\begin{array}{c}\text { Precios } \\
\text { Liniers }\end{array}$ & \multicolumn{1}{c|}{ VBP } \\
\hline Nacimientos Terneros & 12.256 & 200 & 2.451 .200 & 7,17 & 17.575 .104 \\
\hline Nacimientos Terneras & 12.567 & 180 & 2.262 .060 & 6,74 & 15.246 .284 \\
\hline Engorde Novillos y Novillitos & 7.924 & 200 & 1.585 .000 & 5,73 & 9.082 .050 \\
\hline Engorde Vaquillonas & 5.277 & 160 & 844.320 & 5,42 & 4.576 .214 \\
\hline Vacas & 26.654 & 109,5 & 2.918 .613 & 4,38 & 12.783 .525 \\
\hline Totales & 64.678 & & 10.061 .193 & & 59.263 .178 \\
\hline
\end{tabular}

\section{Indicadores de eficiencia actividad ganadera}

Un indicador de la productividad de esta actividad es el engorde de hacienda (kg/cab/año).

Se muestra este indicador para el año 2010 tanto para la región La Plata, Berisso y Ensenada como para la Pcia de Buenos Aires.

\begin{tabular}{|l|r|}
\hline Producción de Carne La Plata, Berisso y Ensenada año 2010 (kg/cab/año) & 155,56 \\
\hline Producción de Carne Pcia de Buenos Aires año 2010 (kg/cab/año) & 152,37 \\
\hline
\end{tabular}


Otro indicador importante (y que se sigue a nivel de la Provincia de Buenos Aires) deviene de la relación entre Terneros/as y Vacas (Tern / Vac).

Este indicador aproxima la posible tasa de destete del partido, es decir, es una medida de eficiencia de la actividad considerando que:

- Hasta 0,5 caracteriza a una zona de baja producción de terneros

- Entre 0,5 y 0,6 es índice de moderada producción de terneros

- Superior a 0,6 buena producción de terneros

Para el año 2010 se observa:

\begin{tabular}{|l|r|}
\hline & \multicolumn{2}{|c|}{ Tern / Vacas } \\
\hline Pcia de Buenos Aires & 0,71 \\
La Plata & 1,01 \\
Berisso & 0,73 \\
Ensenada & 0,49 \\
\hline
\end{tabular}

\section{Actividad Tambera}

La producción láctea de Argentina se concentra en las provincias de Buenos Aires, Santa Fe, Córdoba y Entre Ríos.

Santa Fe es la principal provincia lechera del país, tanto por su volumen de producción como por la importancia que tradicionalmente tuvo la actividad en el desarrollo de algunas ciudades.

La provincia de Córdoba participa con un tercio de la producción nacional, por lo que se ubica en el segundo escalón de las provincias productoras de leche del país. 
Marco Económico del Negocio - Análisis de eficiencia del Sector Primario en la región de La Plata, Berisso y Ensenada

Buenos Aires es la tercera provincia en cuanto a la producción de leche cruda y su participación relativa en el total nacional se ha ido reduciendo a favor de la mayor participación de Santa Fe.

La producción de leche en la provincia de Buenos Aires se encuentra localizada en cinco


cuencas denominadas Abasto Norte, Abasto Sur, Mar y Sierras, Oeste y Sur.

Los partidos de La Plata y Berisso están ubicadas en el área de influencia de la Cuenca Abasto Sur conformada por 17 partidos: La Plata, Brandsen, Berisso, Ensenada, Cañuelas, Castelli, Chascomús, General Belgrano, General Las Heras, General Paz, General Rodríguez, Lobos, Magdalena, Marcos Paz, Monte, Navarro, San Vicente y 25 de Mayo.

En la actualidad, según registros del departamento de lechería del Ministerio de Asuntos Agrarios de la provincia de Buenos Aires, en el territorio de la provincia de Buenos Aires hay 2.626 tambos registrado, distribuidos según las cuencas de la siguiente manera: 
Marco Económico del Negocio - Análisis de eficiencia del Sector Primario en la región de La Plata, Berisso y Ensenada

\begin{tabular}{|c|c|c|}
\hline CUENCA & $\mathbf{N}^{\circ}$ de Tambos & Part sobre el Total \\
\hline Oeste & 1.362 & $51,87 \%$ \\
\hline Abasto Sur & 585 & $22,28 \%$ \\
\hline Abasto Norte & 289 & $11,01 \%$ \\
\hline Mar y Sierras & 241 & $9,18 \%$ \\
\hline Fuera de Cuenca & 76 & $2,89 \%$ \\
\hline Sur & 73 & $2,77 \%$ \\
\hline TOTALES & 2.626 & $100,00 \%$ \\
\hline
\end{tabular}

El partido de La Plata participa dentro de los 585 tambos de la Cuenca a la que pertenece con 19 tambos (3\%) mientras que Berisso sólo lo hace con 1 tambo ${ }^{15}$.

Para el año 2010 en la provincia de Buenos Aires existía una producción primaria de leche aproximada de 2.259 millones de litros por año.

En términos relativos cada cuenca tiene la siguiente participación sobre esa producción anual:

\begin{tabular}{|l|r|}
\hline \multicolumn{1}{|c|}{ CUENCA } & Participación en los litros Prod. \\
\hline Oeste & $55,70 \%$ \\
Abasto Sur & $17,03 \%$ \\
Abasto Norte & $8,40 \%$ \\
Mar y Sierras & $14,36 \%$ \\
Fuera de Cuenca & $4,20 \%$ \\
Sur & $0,31 \%$ \\
\hline \multicolumn{2}{c|}{ TOTALES } \\
\hline
\end{tabular}

La región más importante es la del Oeste en la cual se produce el 55,7\% de la leche, mientras que en segundo lugar se encuentra la Cuenca Abasto Sur con el 17,03\%, correspondiéndole 384,7 millones de litros de los 2.259 millones que se producen en la provincia. Tal situación se explica en la localización de la zona. Esta tiene la ventaja de ser la región más próxima al Gran Buenos Aires y a la Capital Federal.

${ }^{15}$ Ministerio de Asuntos Agrarios de la Provincia de Buenos Aires, departamento de lechería. 
De los 2.259 millones de litros anuales producidos en la provincia de Buenos Aires, La Plata y Berisso producen aproximadamente 13,15 millones de litros que a un precio promedio de $\$ 1,343$ equivalen a $\$ 17.660 .450 .^{16}$

\section{Indicadores de eficiencia actividad tambera}

Un indicador de la productividad de esta actividad está dado por la relación litros por tambo.

Se muestra este indicador para el año 2010 tanto para la región La Plata y Berisso como para la Pcia de Buenos Aires:

Litros año / tambo La Plata + Berisso Año 2010

\section{Actividad Agrícola}

Esta actividad, para la región bajo análisis, resulta de poca significatividad en relación a los volúmenes provinciales.

Para el año 2010 el cultivo de mayor relevancia ha sido el maíz con una Superficie Sembrada de 1.700 has., una Superficie Cosechada de 800 has., una Producción de 6.240 Ton lo que implica un Rendimiento de 7.800 (kg/ha).

En muy menor medida se produjo también Avena y Soja.

\footnotetext{
16 Elaboración propia a partir de información de precios y volúmenes obtenidos desde el Ministerio de Asuntos Agrarios de la Provincia de Buenos Aires, departamento de lechería.
} 
Marco Económico del Negocio - Análisis de eficiencia del Sector Primario en la región de La Plata, Berisso y Ensenada

\begin{tabular}{|l|r|r|r|}
\hline Cultivo & Producción (Tn año 2010) & Precio (Ton) & \multicolumn{1}{c|}{ VBP } \\
\hline Maiz & 6.240 & 501 & 3.126 .240 \\
Avena & 1.386 & 166 & 230.076 \\
Soja & 180 & 1.015 & 182.700 \\
\hline Totales & & & 3.539 .016 \\
\hline
\end{tabular}

Fuente: Elaboración propia sobre la base de datos de Ministerio de Asuntos Agrarios de la Pcia. de Bs. As. y Secretaría de Agricultura de la Nación http://www.siia.gov.ar/sst_pcias/estima/estima.php

La evolución de la producción de Maíz en La Plata ha sido:

Evolución Producción de Maiz en La Plata Tn

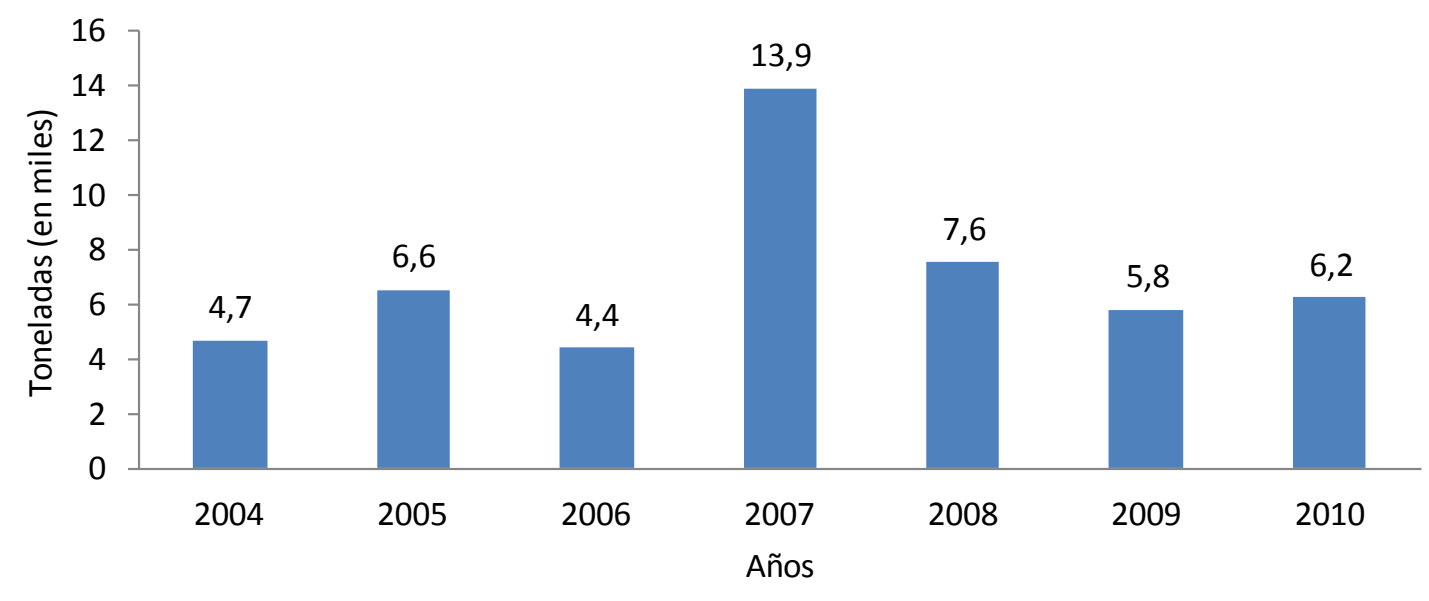

\section{Indicadores de eficiencia actividad agrícola}

Para medir la productividad de la actividad agrícola el indicador por excelencia de rendimiento es la relación quintales por hectárea.

Se muestra este indicador para medir el rendimiento del maíz para los períodos 2006-2010 tanto para el país, la provincia de Buenos Aires y el partido de La Plata. Asimismo se muestra la relación entre estas productividades para La Plata contra el país y para La Plata contra la provincia de Buenos Aires.

La inclusión del país tiene que ver con resaltar el buen desempeño que ha mostrado la provincia de Buenos Aires (de la cual el partido de La Plata forma parte) respecto de la media del país. 


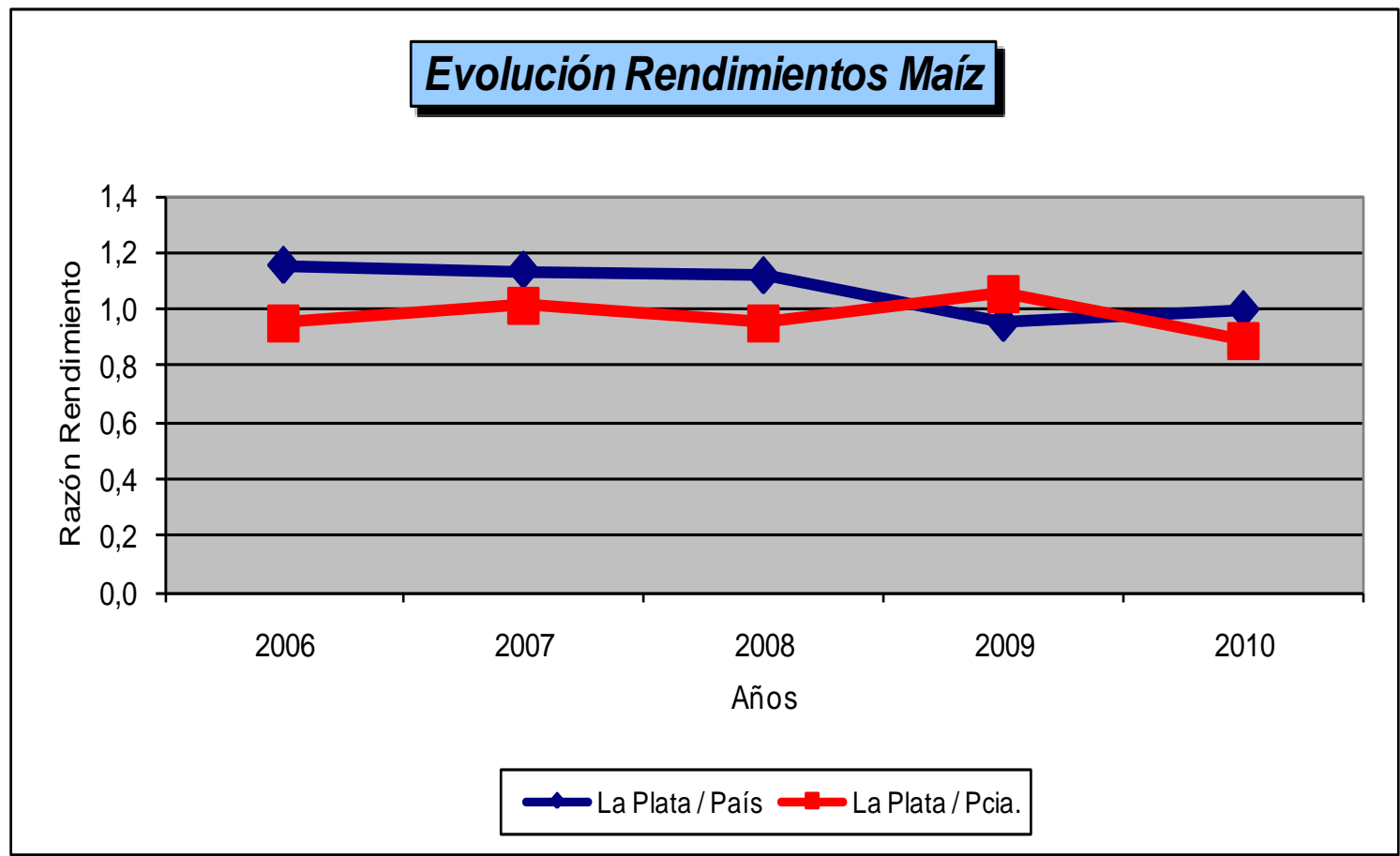

\begin{tabular}{rrrrrr}
\hline Años & $\begin{array}{c}\text { Total País } \\
\text { (qq/ha) }\end{array}$ & $\begin{array}{c}\text { Pcia. de } \\
\text { Buenos } \\
\text { Aires } \\
\text { (qq/ha) }\end{array}$ & $\begin{array}{c}\text { La Plata } \\
\text { (qq/ha) }\end{array}$ & $\begin{array}{c}\text { La Plata } \\
\text { (qq/ha) / } \\
\text { País } \\
\text { (qq/ha) }\end{array}$ & $\begin{array}{c}\text { La Plata } \\
\text { (qq/ha)/ } \\
\text { Pcia. } \\
\text { (qq/ha) }\end{array}$ \\
\hline $\mathbf{2 0 0 6}$ & 59,03 & 71,54 & 68,00 & 1,152 & 0,951 \\
$\mathbf{2 0 0 7}$ & 76,66 & 86,04 & 87,00 & 1,135 & 1,011 \\
$\mathbf{2 0 0 8}$ & 64,52 & 75,52 & 72,00 & 1,116 & 0,953 \\
$\mathbf{2 0 0 9}$ & 55,76 & 50,17 & 53,00 & 0,951 & 1,056 \\
\hline $\mathbf{2 0 1 0}$ & 78,12 & 87,55 & 78,00 & 0,998 & 0,891 \\
\hline
\end{tabular}

Dentro de la provincia de Buenos Aires hay cuatro partidos que son los que muestran los mejores desempeños de rendimiento para los últimos años y que hacen que la provincia en su conjunto se destaque.

Se muestra a continuación el rendimiento para los períodos 2006-2010 de estos partidos de la provincia de Buenos Aires con mejores rindes y la comparación La Plata - Colón, éste último el partido con mejor desempeño promedio para los períodos considerados 
Marco Económico del Negocio - Análisis de eficiencia del Sector Primario en la región de La Plata, Berisso y Ensenada

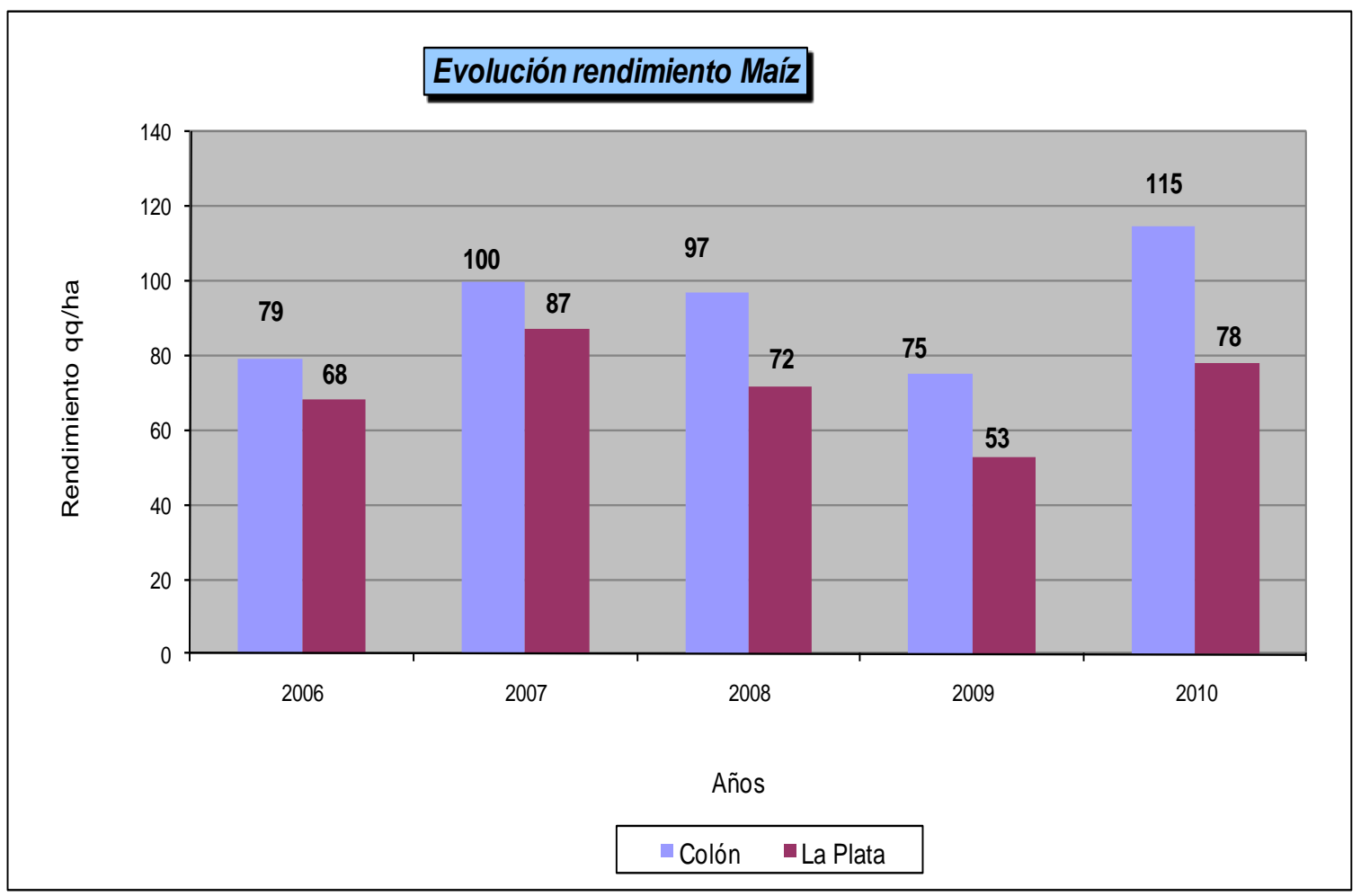

Rendimientos Maíz

\begin{tabular}{rrrrr}
\hline \multicolumn{1}{|c}{ Años } & $\begin{array}{c}\text { Colón } \\
\text { (qq/ha) }\end{array}$ & \multicolumn{1}{c}{$\begin{array}{c}\text { Salto } \\
\text { (qq/ha) }\end{array}$} & $\begin{array}{c}\text { General } \\
\text { Arenales } \\
\text { (qq/ha) }\end{array}$ & $\begin{array}{r}\text { Leandro } \\
\text { N. Alem } \\
\text { (qq/ha) }\end{array}$ \\
\hline $\mathbf{2 0 0 6}$ & 79,01 & 76,00 & 70,00 & 84,00 \\
2007 & 100,00 & 100,00 & 110,00 & 96,00 \\
2008 & 97,00 & 94,00 & 90,00 & 88,00 \\
2009 & 75,00 & 65,00 & 69,00 & 65,20 \\
2010 & 115,01 & 115,00 & 110,00 & 110,00 \\
\hline Promedio & 93,20 & 90,00 & 89,80 & 88,64 \\
\hline
\end{tabular}




\section{Conclusiones}

Los indicadores de eficiencia para las distintas actividades que componen el sector primario de la región de La Plata, Berisso y Ensenada, permiten afirmar que:

- Dentro del sector primario el subsector más importante es el Frutihortícola que representa poco más del $80 \%$ del Valor Bruto de Producción. No sólo destaca por su alta participación en cuanto al VBP sino por ser considerado el cordón Frutihortícola más relevante del AHB y la principal zona productora de hortalizas frescas del país.

El indicador mostrado para la región bajo análisis en su comparación con el del AHB, indica que durante los últimos 12 años la productividad regional ha estado siempre por encima del total provincial. Esto ha hecho que la zona platense marque el impulso del AHB y lo evidencia la relación entre la productividad de La Plata y del AHB siempre por encima de la unidad.

La razón de este continuo incremento de productividad zonal se explica fundamentalmente por la incorporación sostenida de tecnología aplicada al sistema de producción. La incorporación de los invernáculos en el cinturón platense iniciada a fines de la década de los $90^{\prime}$, continúa con fuerte impulso en el año 2010, y la convierte en un cordón productivo de elite en la provincia y en el país.

- El indicador de engorde de hacienda regional es poco más de un $2 \%$ por encima del total provincial.

La Tasa de destete indica que la Pcia de Buenos Aires está considerada dentro del grupo de buena producción de terneros $(0,71)$. La Plata -que concentra el $94 \%$ de la actividad ganadera de la región bajo análisismuestra una relación de 1,01 (42\% mejor a la media provincial). Esto último la ubica junto a los partidos de Rivadavia $(1,26)$, Salto $(1,14)$ y 
Roque Pérez $(1,13)$ entre los que mejores indicadores muestran en este aspecto en la Provincia de Buenos Aires.

Si bien los partidos de La Plata, Berisso y Ensenada representan sólo el $0,41 \%$ de las existencias provinciales los indicadores revelan su buen desempeño respecto del promedio provincial.

- Respecto de la actividad lechera -y a diferencia de lo que ocurre en el sector ganadero donde si bien la importancia relativa regional sobre la provincia de la cual forma parte es baja se destaca a nivel eficiencia por sobre la media provincial quedando dentro del grupo de los partidos con mejor rendimiento-, se observa que la medida de producción de leche por tambos para los partidos de La Plata y Berisso, es un $24 \%$ por debajo del valor de referencia provincial. La importancia relativa regional en esta actividad a nivel provincial alcanza tan sólo el 0,8\%.

- Para los períodos 2006-2010 el rendimiento promedio del maíz (qq / ha) para el país ha sido de 66,82 qq / ha, para la provincia de Buenos Aires de 74,16 qq / ha y para el partido de La Plata de 71,60 qq / ha.

Se destaca el rendimiento provincial respecto de la media del país.

Si bien el rendimiento medio 2006-2010 para el partido de La Plata ha estado en el orden de la media provincial (sólo un 2,75\% por debajo de la misma), ha estado lejos de los partidos provinciales que mejor rendimiento han mostrado tales como Colón, Salto, General Arenales y Leandro Alem, con un rendimiento del orden del $20 \%$ más bajo. 


\section{Bibliografía}

- Andrade Simón (2005) «Diccionario de Economía», Tercera Edición, Editorial Andrade

- Chiavenato Idalberto (2004) «Introducción a la Teoría General de la Administración», Séptima Edición, McGraw-Hill Interamericana

- Dornbusch y Fischer "Macroeconomía" 6 Edición. Mc Graw Hill

- Ferrucci, R. (1992) "Instrumental para el estudio de la economía argentina", Bs. As., Ediciones Macchi

- Koontz Harold y Weihrich Heinz (2004) «Administración Una Perspectiva Global», 12a. Edición, McGraw-Hill Interamericana

- Mankiw Gregory (2004) «Economía», Tercera Edición, McGraw-Hill Interamericana de España

- Monteverde, Ernesto H. (1998) "Conceptos e Interpretación de las Cuentas Nacionales", Bs. As., Ediciones Macchi

- Oliveira Da Silva Reinaldo (2002) «Teorías de la Administración», International Thomson Editores, S.A. de C.V.

- Robbins Stephen y Coulter Mary (2005) «Administración», Octava Edición, Pearson Educación

- Samuelson Paul y Nordhaus William (2002) «Economía», Decimoséptima Edición, McGraw Hill Interamericana de España

- Sistema de Cuenta Nacionales - Rev. 4. Instituto Nacional de Estadística de España (INE) - España. 
- Sistema de Cuentas Nacionales 1993 - CEPAL

- Un Sistema de Cuentas Nacionales. Naciones Unidas - Rev. 4-1993

- Sachs - Larrain (1994) "Macroeconomía en la economía global". Prentice Hall Hispanoamericana S.A.

- García M. y Mierez L. (2006) "Inicio, expansión y características de la tecnología del invernáculo en el Cinturón Hortícola Platense". Boletín Hortícola de la Facultad de Ciencias Agrarias y Forestales (UNLP) - UEEA INTA Gran Buenos Aires y Ministerio de Asuntos Agrarios (Prov. de Buenos Aires). Año $11 \mathrm{~N}^{\circ} 34$ ( $2^{\circ}$ etapa) Diciembre de 2006. ISSN 0328-719X. Pp 410.

- García Matías (2011) Proceso de acumulación de capital en campesinos. El caso de los horticultores bolivianos de Buenos Aires. Cuadernos de Desarrollo rural $\mathrm{N}^{\circ} 66$

- García Matías y Lemmi, S (2011). Territorios pensados, territorios migrados. Una historia de la formación del territorio hortícola platense. VIII Jornadas Patagónicas de Geografía

- García M. (2008) "El factor tierra del cinturón hortícola platense en el marco del nuevo modelo productivo". En V Jornadas de Investigación y Debate "Trabajo, propiedad y tecnología en el mundo rural argentino" - Homenaje al Profesor Miguel Murmis. 23, 24 y 25 de abril de 2008. Universidad Nacional de Quilmes. (Bernal, Buenos Aires)

- Kebat, C. y Paris, H. (2007) "Censo Hortiflorícola 2005. Provincia de Buenos Aires. Principales resultados". Boletín Hortícola de la Facultad de Ciencias Agrarias y Forestales (UNLP) - UEEA INTA Gran Buenos Aires y Ministerio de Asuntos Agrarios (Prov. de Buenos Aires). Año $12^{\circ} 35$ (2etapa) Abril de 2007. Pp 30-32. ISSN 0328-719X. 
Marco Económico del Negocio - Análisis de eficiencia del Sector Primario en la región de La Plata, Berisso y Ensenada

\section{Referencias Web}

http://www.siia.gov.ar/sst pcias/estima/estima.php

http://www.siia.gov.ar/index.php/series-por-tema/ganaderia

http://www.maa.gba.gov.ar/2010/index.php 